\title{
Hydrogen and carbon dioxide recovery from the petrochemical flare gas to methanol production using adsorption and absorption combined high-efficient method
}

\author{
Ali Zare ${ }^{1} \cdot$ Mina Khanipour $^{2} \cdot$ Hojjat Khorrami Sarverstani ${ }^{3} \cdot$ Iman Ahmadi Kakavandi $^{6}$ - Ehsan Javadi Shokroo ${ }^{4,5}$ (D) \\ Mehdi Farniaei $^{5} \cdot$ Mehdi Baghbani $^{6}$
}

Received: 3 February 2019 / Accepted: 1 July 2019 / Published online: 23 July 2019

(c) The Author(s) 2019

\begin{abstract}
Today, one of the challenging issues all over the world is the global warming which can be attributed to the emission of greenhouse gases into the environment as well as burning of gases in flare gas stream of industrial units. The latter can not only cause environmental problems but also is accompanied by wasting a great deal of energy. To deal with the aforementioned issue, the flare gas stream can be recycled after separating some species. In this investigation, the objective is to separate $\mathrm{CO}_{2}$ and $\mathrm{H}_{2}$ from the flare gas in addition to methanol production. In this regard, a separation with sorbent/solvent method is used which is divided into two stages: (1) $\mathrm{H}_{2}$ separation by sorbent, (2) $\mathrm{CO}_{2}$ separation by monoethanolamine solvent. From the obtained results in this study, in the first stage, $\mathrm{H}_{2}$ and $\mathrm{CO}_{2}$ can be purified up to $75 \%$ and $99.83 \%$, respectively. Beside, methanol synthesis is compared in three different cases: (1) industrial unit, (2) $\mathrm{CO}_{2}$ is fed into the reactor instead of $\mathrm{CO}$, and (3) $\mathrm{CO}_{2}$ and $\mathrm{H}_{2}$ are fed to the reactor with stoichiometric coefficients. The obtained methanol production of the case (1) is approximately close to that of the case (3) and it is reduced $4 \%$ in case (3).
\end{abstract}

\section{Graphic abstract}

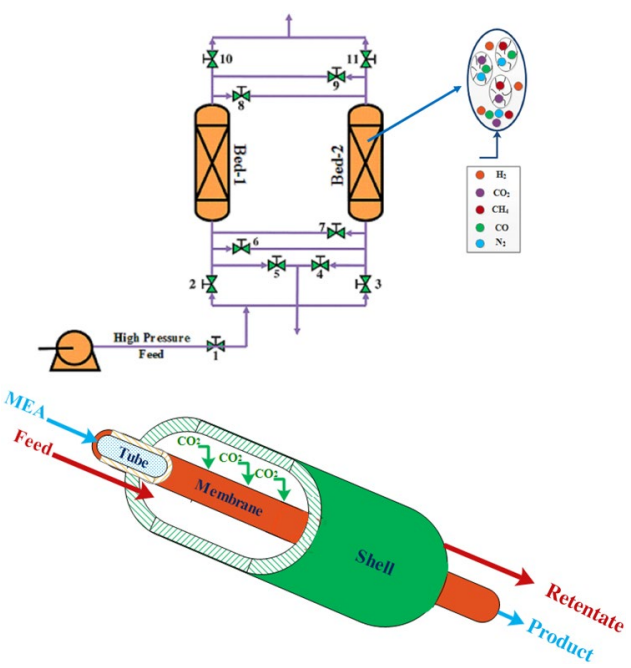

Keywords Flare gas recovery $\cdot$ Methanol production $\cdot \mathrm{H}_{2}$ recovery $\cdot \mathrm{CO}_{2}$ recovery $\cdot$ Pressure swing adsorption $\cdot$

Alkanolamine

Ehsan Javadi Shokroo

javadi@fapkco.ir

Extended author information available on the last page of the article 


\section{Introduction}

\section{Recycling of the flare gas}

In the world, approximately $150-170 \mathrm{~m}^{3}$ of flare gas is burnt or wasted annually which values around 30.6 billion $\$$ and equivalent to $25 \%$ of the gas consumption in the USA, or $30 \%$ of gas consumption in the European Union [1-3]. Gas flaring in different industries is regarded as an integral process and a safety measure in the emergency circumstances, in which a huge volume of the waste gas is exhausted and conducted depressurization $[4,5]$. Nevertheless, in the many industries, owing to improper function of existing units such as cooling units, this current is flowing continuously. Today, this process has led a lot of the environmental problems including emission of greenhouse gases $\left(\mathrm{CH}_{4}\right.$ and $\left.\mathrm{CO}_{2}\right)$ into the environment and other pollutants involving $\mathrm{SO}_{x}$ and $\mathrm{NO}_{x}$ which not only induces air pollution and global warming, but also can result in dangerous diseases for various sorts of living species [2, 4, 6-9]. Also, from an economic prospective, this gas consists of different constituents similar to the natural gas which is a clean and high energy value source of energy [1].

According to the aforementioned economic and environmental issues, attempts are being made with the aim of reducing the amount of flare gas and its utilization in the various industries [2, 5, 10]. Actually, this gas mixture cannot be recycled directly since it contains unsuitable constituents that if recycled to the system can produce undesirable products and decrease the process efficiency [11]. In addition, it cannot be used in the production of chemical materials such as piped natural gas (PNG), liquefied natural gas (LPG), methanol, and ammonia owing to the fact that it is required to eliminate inert gases and separate gas species. In this regard, the various gas separation methods can be applied including cryogenic, membrane, separation with solvents/sorbents which are processed in one stage or multiple stages by considering the type of gas mixture [10, 12]. In this regard, Khanipoor et al. have evaluated separation of purge gas, which is burnt as the flare gas, in methanol synthesis unit through membrane process and its recovery to the steam methane reforming unit and methanol synthesis reactor. In addition, Agahzamin et al. have evaluated the recovery of the purge gas to the auto-thermal reformer (ATR). In both studies, results show that by the recovery of the purge gas not only $\mathrm{CO}_{2}$ emission into the environment is reduced, but also synthesis gas and methanol production enhance very well in terms of quality and quantity, and it is economical as well [13, 14]. A large portion of flare gas contains $\mathrm{CO}, \mathrm{H}_{2}$ and $\mathrm{CO}_{2}$ which can be used in the production of methanol. One of the best methods to separate these species is separation with solvents/sorbents [12], which is explained in the following sections.

\section{Separation with sorbents (adsorption)}

In the industry, adsorption method has developed remarkably since the basis of this method is to select the proper adsorbent and currently it is observed that production of these materials is enhancing noticeably [15, 16]. This method of separation is mainly divided into pressure swing adsorption (PSA), temperature swing adsorption (TSA), vacuum swing adsorption (VSA) and electric swing adsorption (ESA) method [17]. The PSA method is a commercial one which has been studied comprehensively [18, 19] and it is used widely in the purification and separation of $\mathrm{H}_{2}$ from the flare gas as well as steam methane reforming (SMR) processes $[20,21]$. Taking into account the first objective of this study, which is the separation of $\mathrm{H}_{2}$ from the flare gas through PSA process, investigations have been allocated to the evaluation of a gas mixture adsorption analogous to the initial flare gas on different adsorbents. Yang et al. have used a multi-layer bed of zeolite and activated carbon in the room temperature and the pressure of $1-8$ atm to purify $\mathrm{H}_{2}$ from a gas mixture of $\mathrm{CH}_{4} / \mathrm{H}_{2} / \mathrm{CO}_{2} / \mathrm{CO}$. In the study, $\mathrm{H}_{2}$ purity and recovery have reached 99.999 and $60 \%$, respectively [22]. In the mixture of $\mathrm{CH}_{4} / \mathrm{CO}_{2} / \mathrm{CO} / \mathrm{H}_{2} / \mathrm{N}_{2}$, the purification of $\mathrm{H}_{2}$ has been conducted through $\mathrm{CuBTC}$ adsorbent in a fixed-bed tower in four stages. Also, this adsorbent has compared to others and $\mathrm{H}_{2}$ purity has reached $99.9 \%$ [23]. A metal-organic framework, named UTSA-16, is used to eliminate $\mathrm{CO}_{2}$ and $\mathrm{H}_{2}$ purification from the gas mixture and in addition it has been compared to other adsorbents. In this regard, a four-bed PSA cycle for $\mathrm{H}_{2}$ purification from SMR flow is simulated and also this adsorbent is compared to Zeolite 5A and activated carbon BPL. The results show that Zeolite 5A has the highest adsorption rate while in the low pressure the isotherm slope is very sharp which has made the recovery process more difficult. Nevertheless, the activated carbon has the lowest adsorption capacity, but the regeneration process has performed more easily and the UTSA adsorbent has shown a behavior between the two mentioned ones. In this project, purity and recovery of $\mathrm{H}_{2}$ have reached 99.999 and 93-96\%, respectively [24]. The performances of Zeolite $\mathrm{CaX}$ and $5 \mathrm{~A}$ are compared in the separation of $\mathrm{H}_{2}$ from $\mathrm{CO}_{2} / \mathrm{CO} / \mathrm{CH}_{4} / \mathrm{N}_{2}$ through the PSA method and by a simulation tool (PSASIM). The simulation results illustrate that with the pressure of 3 bar of the feed stream, the efficiency of $\mathrm{CaX}$ is higher than $5 \mathrm{~A}$ to recover $\mathrm{H}_{2}$ with the aim of achieving purification of $99.7 \%$. CaX is superior to $5 \mathrm{~A}$ to eliminate $\mathrm{N}_{2}$ while CaX has lower operability to eliminate $\mathrm{CO}$ and $\mathrm{CH}_{4}$ [25]. Hajizadeh et al. [26] evaluated feasibility of three methods for FGR in a giant gas refinery in Iran. They studied liquefaction, LPG production and compression 
in their survey. They reported that the rate of return for liquefaction unit and LPG production unit is more than $200 \%$ for different scenarios and is higher than compression. In 2018, Shokroo applied a PSA pilot plant to simultaneously nitrogen, methane and ethane separation from a flare gas in a domestic industrial petrochemical unit [27]. His PSA unit consists of a 6-step cycle including steps as: pressurization with feed, adsorption, equalization to depressurization, blow down, purge and equalization to pressurization. The simulation results show that the designed system can produce nitrogen with the purity of $99.2 \%$, recovery of $28.3 \%$ and productivity of $26.42 \mathrm{~mol} /\left(\mathrm{kg}_{\text {ads }} \mathrm{h}\right)$. These values are 19.59 , $38.09,6.5821$ for methane and, also 40.74, 43.64, 3.9203 for ethane, respectively.

\section{Separation with solvents (absorption)}

This process is divided into chemical and physical methods $[28,29]$. In the petroleum and chemical industries, chemical absorption through alkanolamines such as monoethanolamine (MEA), diethanolamine (DEA), diisopropanolamine (DIPA) and diglycolamine (DGA) has been used widely to separate or eliminate $\mathrm{CO}_{2}$ from the exhausted gas [29-32]. Amines have long been regarded as good candidates for the purpose of $\mathrm{CO}_{2}$ removal owing to high absorption capacity for $\mathrm{CO}_{2}$ and rapid reaction rates. Among the mentioned amines, MEA is one of the most suitable choices to absorb and recover $\mathrm{CO}_{2}$ [29]. According to the second objective in our investigation which is a separation of $\mathrm{CO}_{2}$ from the flare gas, evaluations are conducted in this regard. The practical processes are used to remove $\mathrm{CO}_{2}$ from the industrial gases and to reduce the emission of greenhouse gases. For this purpose, in mind, design and control of the MEA process are performed simultaneously as well as optimization of an economical process [33]. In the separation of $\mathrm{CO}_{2}$ through amines, specifically MEA, minimization of the energy consumption and improvement of the absorption efficiency have been investigated extensively [34]. A technical and economic method is presented to separate $\mathrm{CO}_{2}$ through the MEA process. Comparison between the cost of present and previous studies over economic and technical operability of the process illustrates that evaluation of this model is appropriate for the MEA process [35].

\section{Methanol}

Methanol is a simple molecule and a multifunctional chemical substance, which is produced generally from the natural gas [36]. Owing to methanol physical and chemical structures, it can be utilized as a clean source of energy, specifically as a suitable fuel for the automobile [37] due to its greater octane number than gasoline and also its easier transportation and storage [36]. It has a large variety of applications and it can be used as a solvent, raw chemical materials production such as formaldehyde and acetic acid in addition to the production of chemical intermediates such as dimethyl terephthalate (DMT) and methyl $t$-butyl $[36,38]$.

Considering the increase in energy cost and environmental issues, more attention has been paid to the methanol as an alternative source of energy owing to its specific characteristics. Methanol can be produced from $\mathrm{CO}, \mathrm{CO}_{2}$ hydrogenation reactions and water gas shift (WGS) reaction as follows:

$$
\begin{aligned}
& \mathrm{CO}+2 \mathrm{H}_{2} \leftrightarrow \mathrm{CH}_{3} \mathrm{OH} \quad \Delta H_{298}^{\circ}=-90.55 \mathrm{~kJ} / \mathrm{mol}, \\
& \mathrm{CO}_{2}+3 \mathrm{H}_{2} \leftrightarrow \mathrm{CH}_{3} \mathrm{OH}+\mathrm{H}_{2} \mathrm{O} \quad \Delta H_{298}^{\circ}=-49.43 \mathrm{~kJ} / \mathrm{mol},
\end{aligned}
$$

$$
\mathrm{CO}_{2}+\mathrm{H}_{2} \leftrightarrow \mathrm{CO}+\mathrm{H}_{2} \mathrm{O} \quad \Delta H_{298}^{\circ}=+41.12 \mathrm{~kJ} / \mathrm{mol} \text {. }
$$

Reactions (1)-(3) are not independent in a way that one is a linear function of the other. In this study, rate expression is selected from Graf et al.'s investigation [39]. Reaction rate equations along with equilibrium rate constants [40] present sufficient information about methanol synthesis kinetics. Reaction rate equations over $\mathrm{CuO} / \mathrm{ZnO} / \mathrm{Al}_{2} \mathrm{O}_{3}$ catalysts are as follows:

$R_{1}=\frac{k_{1} \cdot K_{\mathrm{CO}}}{\Delta}\left[f_{\mathrm{CO}} f_{\mathrm{H}_{2}}^{\frac{3}{2}}-\frac{f_{\mathrm{CH}_{3} \mathrm{OH}}}{K_{\mathrm{p} 1} \cdot f_{\mathrm{H}_{2}}^{\frac{1}{2}}}\right]$,

$R_{2}=\frac{k_{2} \cdot K_{\mathrm{CO}_{2}}}{\Delta}\left[f_{\mathrm{CO}_{2}} \cdot f_{\mathrm{H}_{2}}^{\frac{3}{2}}-\frac{f_{\mathrm{CH}_{3} \mathrm{OH}} \cdot f_{\mathrm{H}_{2} \mathrm{O}}}{K_{\mathrm{p} 2} \cdot f_{\mathrm{H}_{2}}^{\frac{3}{2}}}\right]$,

$R_{3}=\frac{k_{3} \cdot K_{\mathrm{CO}_{2}}}{\Delta}\left[f_{\mathrm{CO}_{2}} \cdot f_{\mathrm{H}_{2}}-\frac{f_{\mathrm{CO}} \cdot f_{\mathrm{H}_{2} \mathrm{O}}}{K_{\mathrm{p} 3}}\right]$,

$\Delta=\left[1+K_{\mathrm{CO}} \cdot f_{\mathrm{CO}}+K_{\mathrm{CO}_{2}} f_{\mathrm{CO}_{2}}\right]\left[f_{\mathrm{H}_{2}}^{\frac{1}{2}}+\frac{K_{\mathrm{H}_{2} \mathrm{O}} \cdot f_{\mathrm{H}_{2} \mathrm{O}}}{K_{\mathrm{H}_{2}}^{\frac{1}{2}}}\right]$.

The rate constant, equilibrium constants, and adsorption constants are enlisted in Table 1, respectively.

Regarding dangers which are attributed to the gas burning as well as the probable advantages of valuable constituents recovery, firstly, the undesirable species in the flare gas of a methanol unit are separated. In this regard, $\mathrm{H}_{2}$ and $\mathrm{CO}_{2}$ recovery from the purge gas has been evaluated through a separation with sorbents/solvents, which is presented in two stages. In the first stage, according to the existing volume

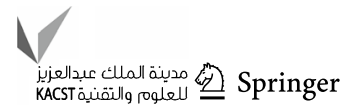


Table 1 The rate, equilibrium, and adsorption/desorption constants of methanol synthesis reactions

\begin{tabular}{|c|c|c|c|c|c|c|c|c|}
\hline \multicolumn{3}{|c|}{ Adsorption constant $K_{i}=A_{i} \exp \left(\frac{B_{i}}{R T}\right)$} & \multicolumn{3}{|c|}{$\begin{array}{l}\text { Equilibrium constant } \\
\log K_{j}=\frac{A_{j}}{T}-B_{j}\end{array}$} & \multicolumn{3}{|c|}{ Rate constant $k_{j}=k_{j 0} \exp \left(\frac{-E_{j}}{R T}\right)$} \\
\hline & $A_{i}^{\mathrm{a}}$ & $B_{i}^{\mathrm{b}}$ & & $A_{j}^{\mathrm{c}}$ & $B_{j}^{\mathrm{d}}$ & & $k_{j 0}^{\mathrm{e}}$ & $E_{j}^{\mathrm{f}}$ \\
\hline$K_{\mathrm{CO}}$ & $(2.16 \pm 0.44) \times 10^{-5}$ & $46.8 \pm 0.8$ & $K_{\mathrm{p} 1}$ & 5139 & 12.621 & $k_{1}$ & $(4.89 \pm 0.29) \times 10^{7}$ & $-63.0 \pm 0.3$ \\
\hline$K_{\mathrm{CO}_{2}}$ & $(7.05 \pm 1.39) \times 10^{-7}$ & $61.7 \pm 0.8$ & $K_{\mathrm{p} 2}$ & 3066 & 10.592 & $k_{2}$ & $(1.09 \pm 0.07) \times 10^{5}$ & $-87.5 \pm 0.3$ \\
\hline$\frac{K_{\mathrm{H}_{2} \mathrm{O}}}{\sqrt{K_{\mathrm{H}_{2}}}}$ & $(6.37 \pm 2.88) \times 10^{-9}$ & $84.0 \pm 1.4$ & $K_{\mathrm{p} 3}$ & -2073 & -2.029 & $k_{3}$ & $(9.64 \pm 7.30) \times 10^{6}$ & $-152.9 \pm 6.8$ \\
\hline
\end{tabular}

of $\mathrm{H}_{2}$ and also its easy separation through the PSA method, this method has been applied. In the second stage, $\mathrm{CO}_{2}$ is separated through a separation with sorbents/solvents. Then, methanol synthesis using $\mathrm{CO}_{2}$ is suggested and evaluated. For the mentioned goal, the required mathematics model along with its validation has been presented.

\section{Process description}

In this investigation, the purge gas stream of Zagros petrochemical company is evaluated, which contains dangerous species flowing to the torch. This gas stream with the flow rate of $910 \mathrm{kmol} / \mathrm{h}$ is mainly composed of $\mathrm{CO}_{2}$ and $\mathrm{H}_{2}$, which can be utilized in the methanol synthesis unit if $\mathrm{CO}_{2}$ and $\mathrm{H}_{2}$ have been recovered and returned to the unit after the undesirable products are removed. The purge gas stream, if burnt completely, can emit approximately 300 ton/day of $\mathrm{CO}_{2}$ into the environment. Also in the presence of $\mathrm{O}_{2}$ and high temperature, $\mathrm{NO}_{x}$ can be produced and emitted into the environment since this stream contains nearly $10 \% \mathrm{~N}_{2}$.

Therefore, in dealing with the above environmental challenges, in this study, a sorbent/solvent separation process according to the previous studies is proposed, to reduce the amount of greenhouse gas emission as well as reusing $\mathrm{CO}_{2}$ and $\mathrm{H}_{2}$. The proposed process is composed of two stages including separation of $\mathrm{H}_{2}$ from the flare gas stream (stage
1) and then separation of $\mathrm{CO}_{2}$ from the mixture of $\mathrm{CO}_{2} / \mathrm{CO} /$ $\mathrm{CH}_{4} / \mathrm{N}_{2}$ (stage2). The whole separation process and methanol production by $\mathrm{CO}_{2}$ are depicted in Fig. 1 .

As it was noted above, the goal in this project is to separate $\mathrm{H}_{2}$ and $\mathrm{CO}_{2}$ from the flare gas mixture. Firstly, regarding the volume of $\mathrm{H}_{2}$ in the stream, a two-bed system PSA process is applied. The simulated PSA process is a six-step process with the following sequence: (1) co-current feed pressurization (PR); (2) high-pressure adsorption (AD) step; (3) counter-current depressurizing pressure equalization (ED) step; (4) counter-current blow down (BD) step; (5) counter-current purge with a light product (PG) step; and (6) co-current pressurizing pressure equalization (EP) step.

The flow diagram of the PSA process is observed in Fig. 2. In each bed, two layers of activated carbon and zeolite $5 \mathrm{~A}$ are placed to separate $\mathrm{H}_{2}$. The sequence time of the PSA process is also depicted in Table 2. Characteristics of the flare gas input feed stream to the PSA unit and the applied parameters for the simulation are tabulated in Tables 3 and 4 , respectively.

The heavy species stream of the first stage is mainly composed of $\mathrm{CO}_{2}, \mathrm{CO}, \mathrm{CH}_{4}$ and $\mathrm{N}_{2}$. Thus, in the second stage, $\mathrm{CO}_{2}$ separation from the mixture is analyzed with MEA solvent.

To explain the solvent separation process, in the first place, the gas stream is entered to the hollow fiber and the solvent is entered co-currently to the tube side. $\mathrm{CO}_{2}$

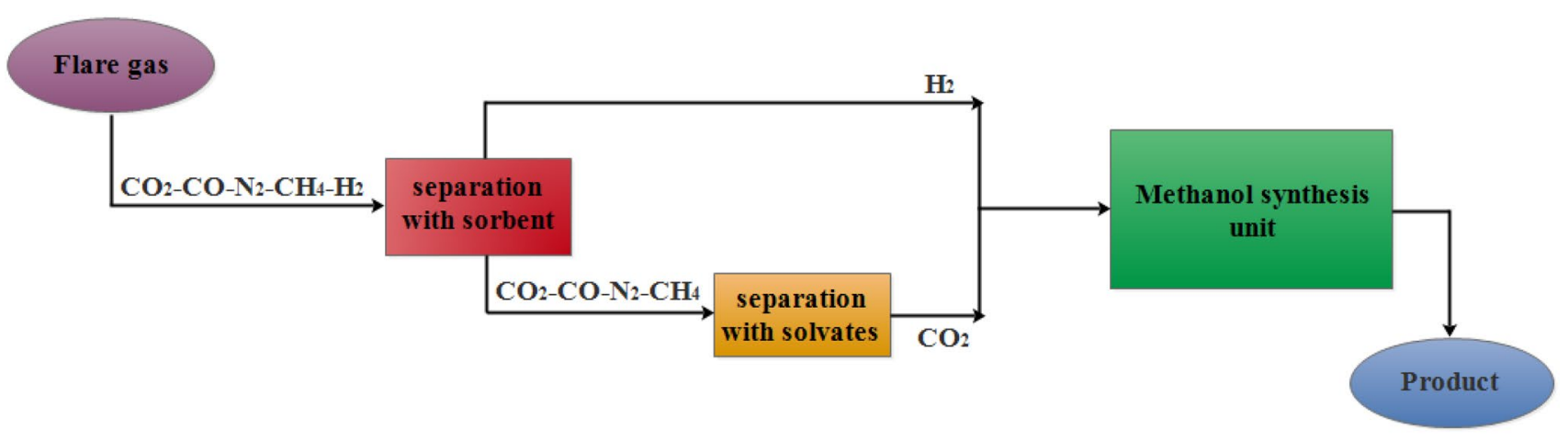

Fig. 1 The schematic diagram of proposed separation configuration and methanol process 


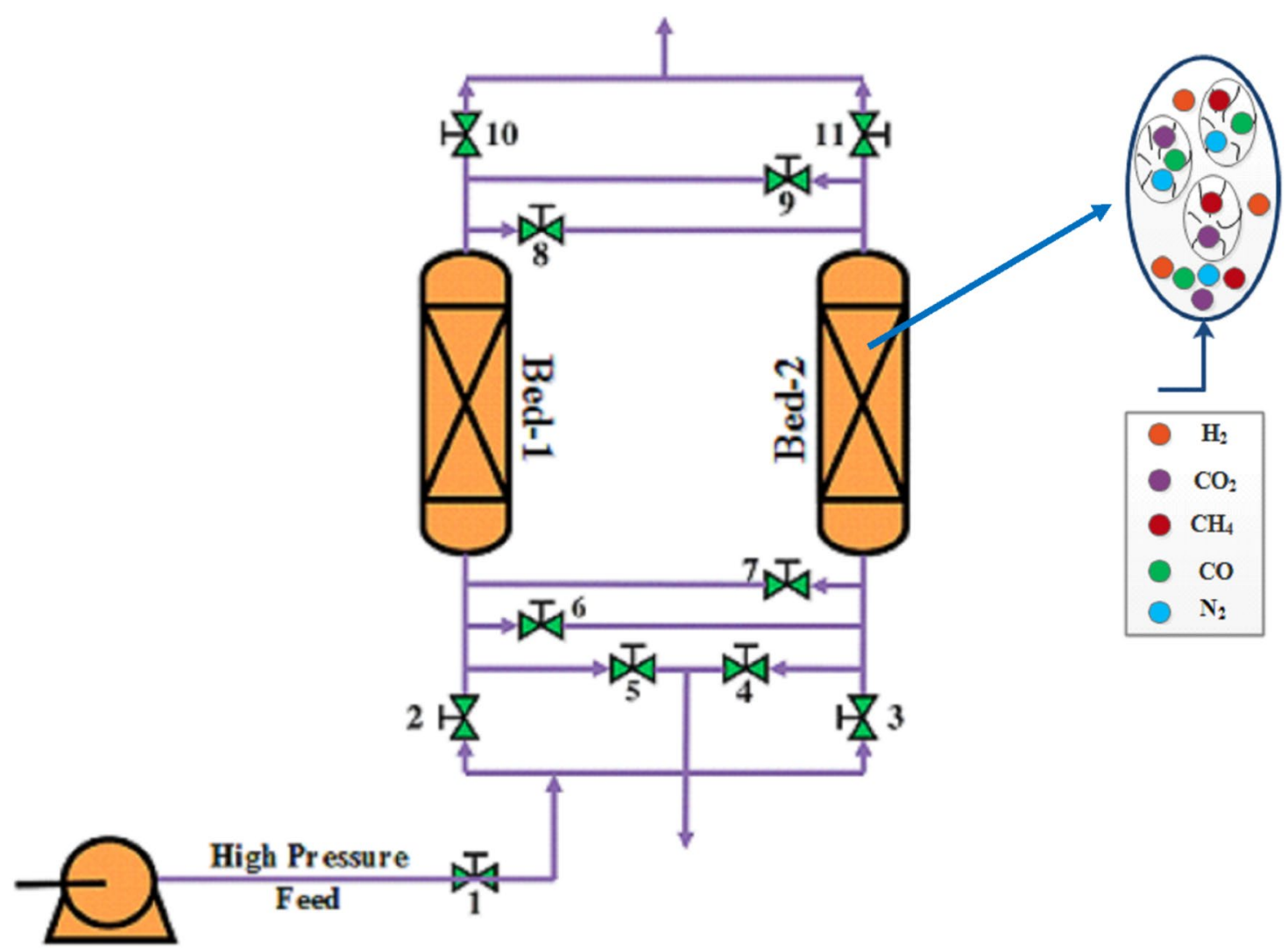

Fig. 2 The overall mechanism of PSA process

permeates to the solvent and then reacts. The retentate of this stage is composed of $\mathrm{CH}_{4}, \mathrm{CO}$ and $\mathrm{N}_{2}$. The rate equations for reaction between $\mathrm{CO}_{2}$ and MEA are as the following, and both equations are proportional to the concentrations with the first order:

$R_{\mathrm{CO}_{2} \text {-MEA }}=k_{r \text {-MEA }}\left[\mathrm{CO}_{2}\right][\mathrm{MEA}]$,

$R_{\mathrm{MEA}}=2 k_{r \text {-MEA }}\left[\mathrm{co}_{2}\right][\mathrm{MEA}]$.

Rate constants, $k_{r}$, are presented in Table 5.

The overall mechanism of this process is shown in Fig. 3. Characteristics of the membrane, input feed stream and applied parameters for the simulation are enlisted in Table 5, respectively.

\section{Modeling}

In the separation with solvent, a heterogeneous steady-state two-dimensional model is used to predict the transfer of $\mathrm{CO}_{2}$ and its distribution in three parts of the tube, membrane and shell (according to Fig. 3). In the separation with the adsorbent (PSA) method, a heterogeneous one-dimensional unsteady-state model is used to predict the diffusion of different species into the adsorbent. In the methanol synthesis reactor, a developed heterogeneous one-dimensional model is applied to determine the concentration distribution and temperature for fluid and solid phases. These three models are simplified based on some of the fundamental presumptions.

\section{Absorption process model ( $\left.\mathrm{CO}_{2}-\mathrm{MEA}\right)$}

Assumptions of this model are as follows:

1. The system is the steady state and the isothermal condition is estimated for that.

2. Ideal gas behavior is applied.

3. Henry's law is applicable for the gas-liquid interface.

4. Fibers distribution is uniform in the shell side.

5. There is no axial diffusion, and mass transfer in the membrane is only taken place through radial diffusion.

6. Happel's free surface theory is used to describe the gas velocity profile.

7. Gas and liquid flow are laminar.

8. $\mathrm{CO}_{2}$ in the liquid phase limits the reaction rate. 
Table 2 Step sequence of the PSA process

\begin{tabular}{|c|c|c|c|c|c|c|}
\hline No. & 1 & 2 & 3 & 4 & 5 & 6 \\
\hline Time (s) & 55 & 30 & 10 & 55 & 30 & 10 \\
\hline Bed 1 & PR & AD & ED & BD & PG & EP \\
\hline Bed 2 & BD & PG & EP & PR & AD & ED \\
\hline SV1 & on & on & off & on & on & off \\
\hline SV2 & on & on & off & off & off & off \\
\hline SV3 & off & off & off & on & on & off \\
\hline SV4 & on & on & off & off & off & off \\
\hline SV5 & off & off & off & on & on & off \\
\hline SV6 & off & off & on & off & off & off \\
\hline SV7 & off & off & off & off & off & on \\
\hline SV8 & off & on & off & off & off & off \\
\hline SV9 & off & off & off & off & on & off \\
\hline SV10 & off & on & off & off & off & off \\
\hline SV11 & off & off & off & off & on & off \\
\hline
\end{tabular}

Table 3 Characteristics of the flare gas input feed stream to the PSA unit [41]

\begin{tabular}{ll}
\hline Parameters & Values \\
\hline Mole flow rate $(\mathrm{kmol} / \mathrm{h})$ & 910 \\
Pressure (bar) & 8 \\
Temperature (K) & 304 \\
Molar fraction (-) & \\
$\mathrm{H}_{2}$ & 0.6098 \\
$\mathrm{CO}_{2}$ & 0.116 \\
$\mathrm{CH}_{4}$ & 0.1094 \\
$\mathrm{~N}_{2}$ & 0.0845 \\
$\mathrm{CO}$ & 0.075 \\
Rest $\left(\mathrm{H}_{2} \mathrm{O}\right.$ and $\left.\mathrm{CH}_{3} \mathrm{OH}\right)$ & $\leq 0.0053$ \\
\hline
\end{tabular}

\section{Tube side equations}

According to the mentioned assumptions, continuity equation from the Fick's law is presented for diffusion and reaction of component $i$ in the tube side as follows:

$D_{i \text {-tube }}\left[\frac{\partial^{2} C_{i \text {-tube }}}{\partial r^{2}}+\frac{1}{r} \frac{\partial C_{i \text {-tube }}}{\partial r}+\frac{\partial^{2} C_{i \text {-tube }}}{\partial z^{2}}\right]+R_{i}=V_{z \text {-tube }} \frac{\partial C_{i \text {-tube }}}{\partial z}$,
Table 4 Parameters for simulation of PSA unit

\begin{tabular}{ll}
\hline Parameters & Values \\
\hline Length, $L(\mathrm{~cm})$ & 360 \\
Inside radius, $R_{\mathrm{B}, i}(\mathrm{~cm})$ & 100 \\
Outside radius, $R_{\mathrm{B}, 0}(\mathrm{~cm})$ & 102 \\
Heat capacity of column, $C_{\mathrm{pw}}(\mathrm{cal} / \mathrm{gr} . \mathrm{k})$ & 0.12 \\
Density of column, $\rho_{w}\left(\mathrm{gr} / \mathrm{cm}^{3}\right)$ & 7.83 \\
Internal heat transfer coefficient, $h_{\mathrm{i}}\left(\mathrm{cal} / \mathrm{cm}^{2} \mathrm{k} \mathrm{s}\right)$ & $9.2 \times 10^{-4}$ \\
External heat transfer coefficient, $h_{\mathrm{o}}\left(\mathrm{cal} / \mathrm{cm}^{2} \mathrm{k} \mathrm{s}\right)$ & $3.4 \times 10^{-4}$ \\
\hline
\end{tabular}

Table 5 Dimensions of the membrane contactor and model parameters

\begin{tabular}{lll}
\hline Parameter & Value & References \\
\hline $\begin{array}{l}\mathrm{CO}_{2} \text { inlet concentration (mol/ } \\
\left.\mathrm{m}^{3}\right)\end{array}$ & 2.48 & In this study \\
Pressure (Pa) & 101,325 & {$[42]$} \\
Temperature (K) & 298.15 & \\
Inner tube diameter (m) & $0.22 \times 10^{-3}$ & \\
Outer tube diameter (m) & $0.30 \times 10^{-3}$ & \\
Inner module diameter (m) & $63.5 \times 10^{-3}$ & \\
Total number of tube & 3600 & \\
Inner shell diameter $(\mathrm{m})$ & $0.529 \times 10^{-3}$ & \\
Module length, $L(\mathrm{~m})$ & 0.2286 & {$[43]$} \\
$D_{\mathrm{CO} 2 \text { shell }}\left(\mathrm{m}^{2} / \mathrm{s}\right)$ & $1.855 \times 10^{-5}$ & {$[44]$} \\
$D_{\mathrm{CO} 2 \text { tube }}\left(\mathrm{m}^{2} / \mathrm{s}\right)$ & $1.925 \times 10^{-9}$ & {$[42]$} \\
$D_{\mathrm{CO} 2 \text { membrane }}\left(\mathrm{m}^{2} / \mathrm{s}\right)$ & $3.85 \times 10^{-3}$ & {$[45]$} \\
$k_{r}\left(\mathrm{~m}^{3} / \mathrm{mol} \mathrm{s}\right)$ for $\mathrm{CO}_{2}-\mathrm{MEA}$ & $10^{(11.916-2382 / \mathrm{T}) / 1000}$ & \\
\hline
\end{tabular}

where $V_{i \text {-tube }}, D_{i \text {-tube }}, C_{i \text {-tube }}$ and $R_{i}$ are the axial velocity, diffusion coefficient, concentration and reaction rate of component $i$ in the tube side, respectively.

If it is considered that the velocity distribution obeys the Newtonian laminar flow in the tube side, it is as follows [46, 47]:

$V_{z \text {-tube }}=2 u_{1}\left[1-\left(\frac{r}{r_{1}}\right)^{2}\right]$.

In the above equation, $u_{1}$ and $r_{1}$ are the gas velocity in the tube side and the inner tube radius, respectively.

\section{Membrane equations}

The continuity equation for $\mathrm{CO}_{2}$ diffusion into the membrane regarding the non-wetting condition in the membrane is as follows:

$D_{i \text {-membrane }}\left[\frac{\partial^{2} C_{i \text {-membrane }}}{\partial r^{2}}+\frac{1}{r} \frac{\partial C_{i \text {-membrane }}}{\partial r}+\frac{\partial^{2} C_{i \text {-membrane }}}{\partial z^{2}}\right]=0$, 


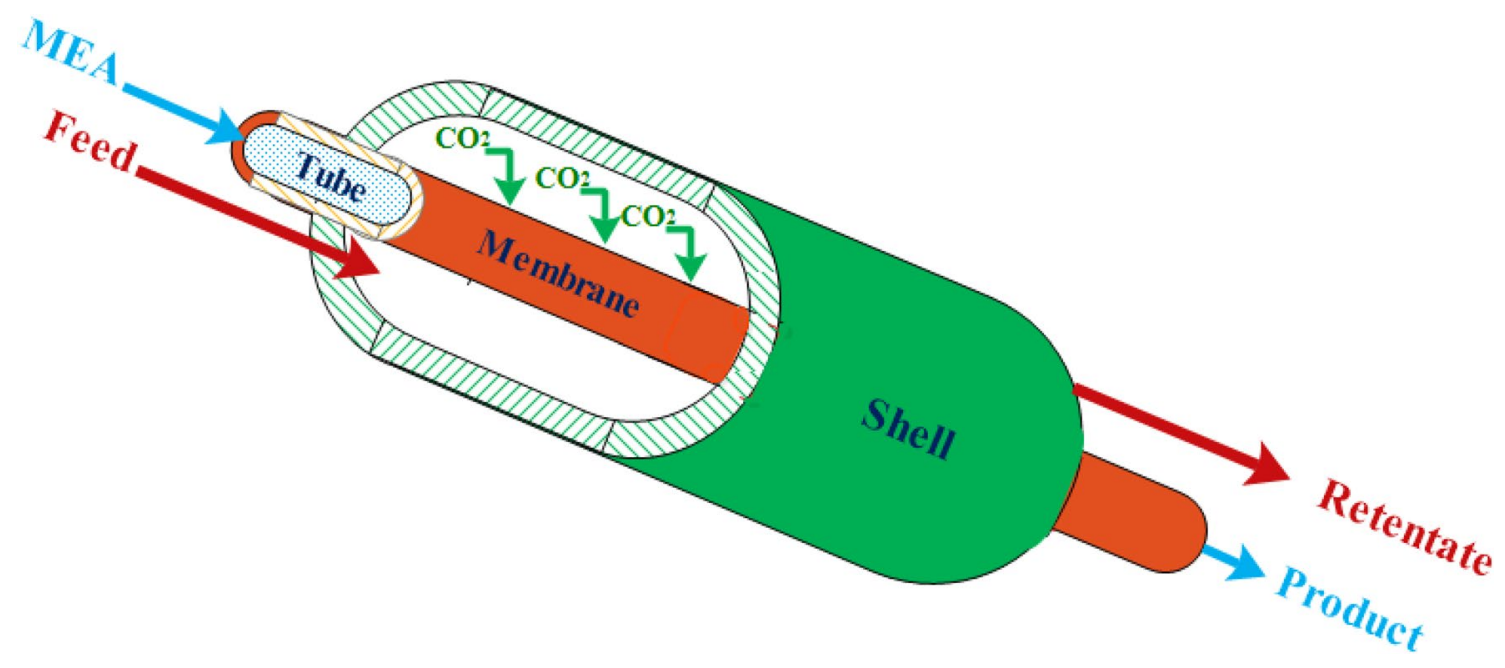

Fig. 3 The overall mechanism of $\mathrm{CO}_{2}$ chemical absorption process

$D_{i \text {-membrane }}$ is the diffusion coefficient of component $i$ in the membrane.

\section{Shell side equation}

The continuity equation in the shell side (where gas is flowing and there is no reaction) to estimate the diffusion flux of component $i$ is presented as follows:

$V_{z \text {-shell }} \frac{\partial C_{i \text {-shell }}}{\partial z}=D_{i \text {-shell }}\left[\frac{\partial^{2} C_{i \text {-shell }}}{\partial r^{2}}+\frac{1}{r} \frac{\partial C_{i \text {-shell }}}{\partial r}+\frac{\partial^{2} C_{i \text {-shell }}}{\partial z^{2}}\right]$,

where $V_{z \text {-shell }}$ and $D_{i \text {-shell }}$ are the axial velocity and diffusion coefficient of component $i$ in the shell side, respectively. According to Happel's free surface theory, the velocity profile in the shell side is as follows [48, 49]:

$V_{z \text {-shell }}=2 u\left[1-\left(\frac{r_{2}}{r_{3}}\right)^{2}\right] \times\left[\frac{\left(\frac{r_{2}}{r_{3}}\right)^{2}-\left(\frac{r_{2}}{r_{3}}\right)^{2}+2 \ln \left(\frac{r_{2}}{r}\right)}{3+\left(\frac{r_{2}}{r_{3}}\right)^{4}-4\left(\frac{r_{2}}{r_{3}}\right)^{2}+4 \ln \left(\frac{r_{2}}{r_{3}}\right)}\right]$.

In the above equation, $u$ and $r_{2}$ are the average gas velocity in the shell side and the outer tube radius, respectively. Also, the relation between $r_{1}$ and $r_{2}$ is defined through Eq. (15) [50]:

$r_{3}=r_{2} \sqrt{1 /(1-\varphi)}$,

where $\varphi$ is the volume fraction of the void space and it can be calculated through the following Eq. (16):

$\varphi=1-\frac{n r_{2}^{2}}{r_{3}^{2}}$ where $n$ and $r_{3}$ are the fiber number and the inner shell radius, respectively.

\section{PSA process model}

The assumptions that used for the PSA model are as follows:

1. Ideal gas behavior is used.

2. The total pressure during the adsorption and desorption steps remains constant with the time.

3. The total pressure changes non-linearly versus time during pressurization, pressure equalization to pressurization and blow down steps.

4. The flow pattern is assumed to be axially displaced plugflow model.

5. Equilibrium relations for $\mathrm{H}_{2}, \mathrm{CO}_{2}, \mathrm{CO}, \mathrm{CH}_{4}$ and $\mathrm{N}_{2}$ are stated by the multi-component Langmuir-Freundlich isotherm.

6. Linear driving force (LDF) relation is used for the rate of mass transfer.

According to the above statements, the dynamic behavior of the PSA process is presented in the basis of mass, energy and momentum balances as of the following.

\section{Mass balance}

The mass balance of $i$ th component for the gas phase in the adsorption bed is presented through Eq. (17) [51, 52]:

$$
\begin{gathered}
-D_{\mathrm{L}} \frac{\partial^{2} y_{i}}{\partial z^{2}}+y_{i} \cdot \frac{\partial u}{\partial z}+u \cdot\left(\frac{\partial y_{i}}{\partial z}+y_{i} \cdot\left(\frac{1}{P} \cdot \frac{\partial P}{\partial z}-\frac{1}{T} \cdot \frac{\partial T}{\partial z}\right)\right)+\frac{\partial y_{i}}{\partial t} \\
+y_{i}\left(\frac{1}{P} \cdot \frac{\partial P}{\partial t}-\frac{1}{T} \cdot \frac{\partial T}{\partial t}\right)+\left(\frac{\rho_{\mathrm{p}} \cdot R \cdot T}{P}\right) \cdot\left(\frac{1-\varepsilon}{\varepsilon}\right) \cdot \frac{\partial \bar{q}_{i}}{\partial t}=0,
\end{gathered}
$$


Table 6 Langmuir-Freundlich parameters and LDF coefficients for activated carbon and zeolite $5 \mathrm{~A}$

\begin{tabular}{|c|c|c|c|c|c|c|c|}
\hline & $K_{1}(\mathrm{mmol} / \mathrm{g})$ & $\begin{array}{l}K_{2} \times 10^{2} \\
\left(\mathrm{mmol} \mathrm{g}^{-1}\right. \\
\left.\mathrm{K}^{-1}\right)\end{array}$ & $k_{3} \times 10^{4}(1 / \mathrm{atm})$ & $k_{4}(\mathrm{~K})$ & $k_{5}(-)$ & $k_{6}(\mathrm{~K})$ & LDF coeff. $\omega_{i}(\mathrm{~s})$ \\
\hline \multicolumn{8}{|c|}{ Activated carbon } \\
\hline $\mathrm{H}_{2}$ & 16.943 & -2.100 & 0.625 & 1229 & 0.980 & 43.03 & 0.700 \\
\hline $\mathrm{CH}_{4}$ & 23.860 & -5.621 & 34.780 & 1159 & 1.618 & -248.9 & 0.195 \\
\hline $\mathrm{CO}$ & 33.850 & -9.073 & 2.311 & 1751 & 3.053 & -654.4 & 0.150 \\
\hline $\mathrm{N}_{2}$ & 1.644 & -0.073 & 545.0 & 326 & 0.908 & 0.991 & 0.261 \\
\hline $\mathrm{CO}_{2}$ & 28.797 & -7.000 & 100.0 & 1030 & 0.999 & -37.04 & 0.036 \\
\hline \multicolumn{8}{|c|}{ Zeolite 5A } \\
\hline $\mathrm{H}_{2}$ & 4.314 & -1.060 & 25.15 & 458 & 0.986 & 43.03 & 0.700 \\
\hline $\mathrm{CH}_{4}$ & 5.833 & -1.192 & 6.507 & 1731 & 0.820 & 53.15 & 0.147 \\
\hline $\mathrm{CO}$ & 11.845 & -3.130 & 202.0 & 763 & 3.823 & -931.3 & 0.063 \\
\hline $\mathrm{N}_{2}$ & 4.813 & -0.668 & 5.695 & 1531 & 0.842 & -7.467 & 0.099 \\
\hline $\mathrm{CO}_{2}$ & 10.030 & -1.858 & 1.578 & 207 & -5.648 & 2098.0 & 0.014 \\
\hline
\end{tabular}

where $\partial \bar{q}_{i}$ in the above equations is described through LDF relation as follows:

$\frac{\partial \bar{q}_{i}}{\partial t}=\omega_{i}\left(\dot{q}_{i}-\bar{q}_{i}\right)$.

In this equation, $\omega_{i}$ is the LDF coefficient of $i$ th component and $\dot{q}_{i}$ is the concentration of $i$ th component in the solid phase. The equilibrium concentration of $i$ th adsorbed component in the solid phase relates to its gas phase concentration through the following Langmuir-Freundlich isotherm:

$\dot{q}_{i}=\frac{q_{m, i} \cdot B_{i} \cdot P_{i}^{n i}}{1+\sum_{j=1}^{N} B_{j} \cdot P_{j}^{n j}}$,

where $q_{m, i}$ is the saturation concentration in the solid phase and defined as follows:

$q_{m, i}=k_{1, i}+k_{2, i} T$.

Also, $B_{i}$ and $n_{i}$ are determined through the following relations:

$B_{i}=k_{3, i} \cdot \exp \left(k_{4, i} / T\right)$,

$n_{i}=k_{5, i}+\frac{k_{6, i}}{T}$,

where $k_{1, i}, k_{2, i}, k_{3, i}, k_{4, i}, k_{5, i}$, and $k_{6, i}$ are the parameters of Langmuir-Freundlich equation and $T$ is the system temperature.

According to relation (23), $\omega_{i}$ is considered as a function of $i$ th component concentration [53]

$\omega_{i}=C_{i} \cdot P_{r}^{0.5} \cdot\left(1+B_{i} \cdot P_{i}\right)^{2}$

In this equation, $C_{i}$ is the diffusion time constant for the component $i, P_{i}$ is the partial pressure of component $i$, and $B_{i}$ is the parameter of Langmuir-Freundlich equation. The
Langmuir-Freundlich parameters and the LDF Coefficients for Activated Carbon and Zeolite 5A are listed in Table 6. Table 7 shows the characteristics of the adsorbents.

\section{Energy balance}

The energy balance according to the mentioned assumptions is as follows $[54,55]$ :

$$
\begin{aligned}
- & K_{\mathrm{L}} \frac{\partial^{2} T}{\partial z^{2}}+\varepsilon \cdot \rho_{\mathrm{g}} \cdot c_{\mathrm{p}, \mathrm{g}} \cdot\left(u \frac{\partial T}{\partial z}+T \frac{\partial u}{\partial z}\right)+\left(\varepsilon_{\mathrm{t}} \cdot \rho_{\mathrm{g}} \cdot c_{\mathrm{p}, \mathrm{g}}+\rho_{\mathrm{B}} \cdot c_{\mathrm{p}, \mathrm{s}}\right) \cdot \frac{\partial T}{\partial t} \\
- & \rho_{\mathrm{B}} \cdot \sum_{i=1}^{N}\left(\frac{\partial \bar{q}_{i}}{\partial t} \cdot\left(-\Delta \bar{H}_{i}\right)\right)+\frac{2 h_{i}}{R_{\mathrm{B}, \mathrm{i}}}\left(T-T_{\mathrm{W}}\right)=0 .
\end{aligned}
$$

In this equation, $K_{\mathrm{L}}$ is the axial thermal dispersion coefficient, $\rho_{\mathrm{g}}$ is the gas phase density, $\rho_{\mathrm{B}}$ is the bulk density, $c_{\mathrm{p}, \mathrm{g}}$ is the heat capacity of the gas, $c_{\mathrm{p}, \mathrm{s}}$ is the heat capacity of the solid phase (adsorbent), $\Delta \bar{H}_{i}$ is the enthalpy change of adsorption for component $i, \varepsilon_{\mathrm{t}}$ is the total porosity coefficient, $h_{i}$ is the heat transfer coefficient in the adsorption bed, $R_{\mathrm{B}, \mathrm{i}}$ is the internal bed radius and $T_{\mathrm{w}}$ is the bed wall temperature.

The energy equation for heat transfer from the bed wall is as follows:

Table 7 Characteristics of the adsorbents

\begin{tabular}{lll}
\hline Adsorbent & Activated carbon & Zeolite $5 \mathrm{~A}$ \\
\hline Type & Granular & Sphere \\
Normal pellet size $(\mathrm{mesh})$ & $6-16$ & $4-8$ \\
Average pellet size,$R_{\mathrm{p}}(\mathrm{cm})$ & 0.115 & 0.157 \\
Pellet density, $F_{\mathrm{p}}\left(\mathrm{g} / \mathrm{cm}^{3}\right)$ & 0.85 & 1.16 \\
Heat capacity, $C_{\mathrm{ps}}\left(\mathrm{cal} \mathrm{g}^{-1} \mathrm{~K}^{-1}\right)$ & 0.25 & 0.22 \\
Particle porosity, $R(-)$ & 0.61 & 0.65 \\
Bed density, $F_{\mathrm{B}}\left(\mathrm{g} / \mathrm{cm}^{3}\right)$ & 0.482 & 0.746
\end{tabular}


$\frac{\partial T_{\mathrm{w}}}{\partial t}=\left[\frac{2 \pi \cdot R_{\mathrm{B}, \mathrm{i}} \cdot h_{i}}{\rho_{\mathrm{w}} \cdot c_{\mathrm{p} \cdot \mathrm{w}} \cdot A_{\mathrm{w}}}\right] \cdot\left(T-T_{\mathrm{w}}\right)-\left[\frac{2 \pi \cdot R_{\mathrm{B}, \mathrm{o}} \cdot h_{\mathrm{o}}}{\rho_{\mathrm{w}} \cdot c_{\mathrm{p} \cdot \mathrm{w}} \cdot A_{\mathrm{w}}}\right] \cdot\left(T_{\mathrm{w}}-T_{\mathrm{atm}}\right)$.

In this equation $A_{w}$ is the cross-sectional area of the bed, which is defined as follows:

$$
A_{\mathrm{w}}=\pi \cdot\left(R_{\mathrm{B}, \mathrm{o}}^{2}-R_{\mathrm{B}, \mathrm{i}}^{2}\right)
$$

\section{Momentum equation}

The continuity equation or overall mass transfer of the gas phase is as follows:

$$
\begin{aligned}
& \frac{\partial P}{\partial t}-D_{\mathrm{L}} \frac{\partial^{2} P}{\partial z^{2}}+P \frac{\partial u}{\partial z}+u \frac{\partial P}{\partial z}+P T \cdot\left(-D_{\mathrm{L}} \frac{\partial^{2}}{\partial z^{2}}\left(\frac{1}{T}\right)+\frac{\partial}{\partial t}\left(\frac{1}{T}\right)+u \frac{\partial}{\partial z}\left(\frac{1}{T}\right)\right) \\
& -z \cdot D_{\mathrm{L}} \cdot T \cdot \frac{\partial P}{\partial z} \cdot \frac{\partial}{\partial z}\left(\frac{1}{T}\right)+\rho_{\mathrm{p}} \cdot R \cdot t \cdot\left(\frac{1-\varepsilon}{\varepsilon}\right) \cdot \sum_{i=1}^{N} \frac{\partial \bar{q}_{i}}{\partial t}=0
\end{aligned}
$$

where the total pressure drop along the bed is calculated using the Ergun equation, and the total pressure drop versus time is estimated through a quadratic equation $[56,57]$.

$-\frac{\mathrm{d} P}{\mathrm{~d} z}=a \cdot \mu \cdot u+b \cdot \rho \cdot u \cdot|u|$,

$$
P(t)=A \cdot t^{2}+B \cdot t+C
$$

Table 8 Boundary conditions for each stage of PSA unit

$Z=0 \quad Z=L$

Pressurization with feed

$$
\begin{array}{ll}
-D_{\mathrm{L}}\left(\frac{\partial y_{i}}{\partial z}\right)=u \cdot\left(y_{i\left(z=0^{-}\right)}-y_{i\left(z=0^{+}\right)}\right) & \frac{\partial y_{i}}{\partial z}=0 \\
-K\left(\frac{\partial T}{\partial z}\right)=\rho_{\mathrm{g}} \cdot c_{\mathrm{p} \cdot \mathrm{g}} \cdot u \cdot\left(T_{i\left(z=0^{-}\right)}-T_{i\left(z=0^{+}\right)}\right) & \frac{\partial T}{\partial z}=0 \\
u=u_{\text {Feed }} & u=0
\end{array}
$$

High pressure adsorption

$$
\begin{aligned}
& -D_{\mathrm{L}}\left(\frac{\partial y_{i}}{\partial z}\right)=u \cdot\left(y_{i\left(z=0^{-}\right)}-y_{i\left(z=0^{+}\right)}\right) \\
& -K\left(\frac{\partial T}{\partial z}\right)=\rho_{\mathrm{g}} \cdot c_{\mathrm{p} \cdot \mathrm{g}} \cdot u \cdot\left(T_{i\left(z=0^{-}\right)}-T_{i\left(z=0^{+}\right)}\right) \\
& u=u_{\text {Feed }}
\end{aligned}
$$

$Z=L$

Equalization to depressurization

$$
\begin{aligned}
& \frac{\partial y_{i}}{\partial z}=0 \\
& \frac{\partial T}{\partial z}=0 \\
& \frac{\partial u}{\partial z}=0
\end{aligned}
$$

$$
\begin{aligned}
& \frac{\partial y_{i}}{\partial z}=0 \\
& \frac{\partial T}{\partial z}=0 \\
& \frac{\partial u}{\partial z}=0 \\
& \frac{\partial y_{i}}{\partial z}=0 \\
& \frac{\partial T}{\partial z}=0 \\
& u=0
\end{aligned}
$$

Blow down

$$
\begin{gathered}
\frac{\partial y_{i}}{\partial z}=0 \\
\frac{\partial T}{\partial z}=0 \\
\frac{\partial u}{\partial z}=0 \\
\text { Purge } \\
\frac{\partial y_{i}}{\partial z}=0 \\
\frac{\partial T}{\partial z}=0 \\
\frac{\partial u}{\partial z}=0
\end{gathered}
$$

Equalization to pressurization

$$
\begin{aligned}
& -D_{\mathrm{L}}\left(\frac{\partial y_{i}}{\partial z}\right)=u \cdot\left(y_{i\left(z=0^{-}\right)}-y_{i\left(z=0^{+}\right)}\right) \\
& -K_{\mathrm{L}}\left(\frac{\partial T}{\partial z}\right)=\rho_{\mathrm{g}} \cdot c_{\mathrm{p}, \mathrm{g}} \cdot u \cdot\left(y_{i\left(z=0^{-}\right)}-y_{i\left(z=0^{+}\right)}\right) \\
& u=u^{\mathrm{ED}}
\end{aligned}
$$


where $A, B$ and $C$ in Eq. (30) are calculated based on the initial and final pressures of each PSA step.

According to the PSA process, boundary conditions for each step are enlisted in Table 8.

\section{Methanol synthesis reactor model}

This model is proposed through some assumptions which are summarized below:

1. Steady-state conditions are applied.

2. Ideal gas behavior is used.

3. Axial pressure drop is negligible and is calculated in the reaction side of the methanol reactor by the Ergun equation.

4. The flow pattern is described through axially dispersed plug-flow model.

5. In the methanol synthesis reactor, bed porosity is considered axial and radial and remains constant.

6. The reaction is considered over the catalyst bed, and reaction in the gas phase can be ignored.

7. The temperature gradient in the catalyst is ignored owing to the small size of the catalyst.

\section{Mass and energy balances in the catalyst phase}

$a_{\mathrm{v}} c_{j} k_{\mathrm{g}, i}\left(y_{i}^{\mathrm{g}}-y_{i}^{\mathrm{s}}\right)+\eta r_{i} \rho_{\mathrm{b}}=0$,

$a_{\mathrm{v}} h_{\mathrm{f}}\left(T^{\mathrm{g}}-T^{\mathrm{s}}\right)+\eta \rho_{\mathrm{b}} \sum_{i=1}^{\mathrm{NC}} r_{i}\left(-\Delta H_{\mathrm{f}, i}\right)=0$

where $T^{\mathrm{s}}$ and $y_{i}^{\mathrm{s}}$ are the surface temperature and mole fraction of component $i$ in the solid phase, respectively. $T^{\mathrm{g}}$ and $y_{i}^{\mathrm{g}}$ are those in the fluid phase, and $\eta$ is the effectiveness factor which could be obtained from the dusty gas model.

\section{Mass and energy balances in the fluid phase}

$$
\begin{aligned}
& -\frac{F_{\mathrm{t}}}{A_{\mathrm{c}}} \frac{\mathrm{d} y_{i}^{\mathrm{g}}}{\mathrm{d} z}+a_{\mathrm{v}} c_{j} k_{\mathrm{g}, i}\left(y_{i}^{\mathrm{s}}-y_{i}^{\mathrm{g}}\right)-\varphi \frac{J_{i}}{A_{\mathrm{c}}}=0, \\
& \mathrm{~d} F_{\mathrm{t}}=\sum_{i=1}^{\mathrm{NC}} \mathrm{d} F_{i}, \\
& -\frac{F_{\mathrm{t}} \cdot C_{\mathrm{p}}^{\mathrm{g}}}{A_{\mathrm{c}}} \frac{\mathrm{d} T^{\mathrm{g}}}{\mathrm{d} z}+a_{\mathrm{v}} h_{\mathrm{f}}\left(T^{\mathrm{s}}-T^{\mathrm{g}}\right) \pm \frac{\pi D_{i}}{A_{\mathrm{c}}} U_{2-3}\left(T_{3}^{\mathrm{g}}-T_{2}^{\mathrm{g}}\right) \\
& \quad-\varphi \frac{J_{i}}{A_{\mathrm{c}}} \int_{T^{\mathrm{m}}}^{T^{\mathrm{g}}} C_{\mathrm{p}, 1} \mathrm{~d} T \pm \frac{\pi D_{i}}{A_{\mathrm{c}}} U_{2-1}\left(T_{2}^{\mathrm{g}}-T_{1}^{\mathrm{g}}\right)=0 .
\end{aligned}
$$

$T^{\mathrm{g}}$ and $y_{i}^{\mathrm{g}}$ are the temperature and molar fraction of component $i$ in the fluid phase, respectively. The energy Eq. (35) shows convectional heat transfer between the fluid and solid phases, and heat transfer between two sides of shell and tube.

\section{Solution method}

To simulate the separation with sorbents/solvents method and develop its mathematical model, a set of partial differential equations and algebraic equations are used. To solve the partial differential equations, firstly, the mentioned equations transformed into the algebraic equations through implicit finite difference scheme, and then in the PSA process the algebraic equations are solved through Newton-Raphson scheme for each given time. For the $\mathrm{CO}_{2}-\mathrm{MEA}$ process, the linearized algebraic equations in the radial direction that form a tridiagonal matrix are solved simultaneously by the Thomas algorithm. In the synthesis methanol reactor, Guess-Newton method is applied to solve the attained equations using finite difference approximation. In this regard, the reactor length is divided into 100 segments and the obtained results from each segment are used as the input condition for the next segment.

\section{Base case}

The first calculations are made on a reference case which is required to start the simulation and is followed by the evaluation of different parameters effects. Actually, this is called the base case. Operational conditions which are used for the PSA process in this study is based on Jee et al. [58] investigation, and in the second stage, that of the process of $\mathrm{CO}_{2}$-MEA is based on Marzouqi et al. [42] study, and that of methanol synthesis process is based on what is proposed in the industry (represented in Table 9).

\section{Model validation}

To validate the obtained results of numerical simulation, the results of the mathematical model are compared with the empirical data. In this regard, for the PSA process, the results of Jam's $\mathrm{H}_{2}$ purification industrial unit are used [60]. Figure 4 illustrates $\mathrm{H}_{2}$ purity as a function of input feed flow rate to the PSA unit along with the industrial data. Besides, it can be observed that industrial results are in good agreement with that of the mathematical model and this confirmed in the results of other investigations [61, 62]. 
Table 9 Characteristics of the methanol synthesis reactor and input feed stream to that [59]

\begin{tabular}{|c|c|c|}
\hline Parameter & Value & Unit \\
\hline \multicolumn{3}{|l|}{ Gas phase } \\
\hline \multicolumn{3}{|l|}{ Feed composition (mole fraction) } \\
\hline $\mathrm{CH}_{3} \mathrm{OH}$ & 0.0050 & \\
\hline $\mathrm{CO}_{2}$ & 0.0940 & \\
\hline $\mathrm{CO}$ & 0.0460 & \\
\hline $\mathrm{H}_{2} \mathrm{O}$ & 0.0004 & \\
\hline $\mathrm{H}_{2}$ & 0.6590 & \\
\hline $\mathrm{N}_{2}$ & 0.0930 & \\
\hline $\mathrm{CH}_{4}$ & 0.1026 & \\
\hline Total molar flow rate & 0.64 & $\mathrm{~mol} / \mathrm{s}$ \\
\hline Inlet pressure & 76.98 & bar \\
\hline \multicolumn{3}{|l|}{ Catalyst particle } \\
\hline Density & 1770 & $\mathrm{~kg} / \mathrm{m}^{3}$ \\
\hline Particle diameter & $5.47 \times 10^{-3}$ & $\mathrm{~m}$ \\
\hline Heat capacity & 5.0 & $\mathrm{~kJ} / \mathrm{kg} \mathrm{K}$ \\
\hline Thermal conductivity & 0.004 & $\mathrm{~W} / \mathrm{m} \mathrm{K}$ \\
\hline Specific surface area & 626.98 & $\mathrm{~m}^{2} / \mathrm{m}^{3}$ \\
\hline $\begin{array}{l}\text { Ratio of void fraction to tortuosity of } \\
\text { catalyst particle }\end{array}$ & 0.123 & \\
\hline Length of reactor & 7.022 & $\mathrm{~m}$ \\
\hline Number of tube & 2962 & \\
\hline Bed void fraction & 0.39 & \\
\hline Density of catalyst bed & 1140 & $\mathrm{~kg} / \mathrm{m}^{3}$ \\
\hline Tube inner diameter & $3.8 \times 10^{-2}$ & $\mathrm{~m}$ \\
\hline Tube outer diameter & $4.2 \times 10^{-2}$ & $\mathrm{~m}$ \\
\hline Wall thermal conductivity & 48 & $\mathrm{~W} / \mathrm{m} \mathrm{K}$ \\
\hline
\end{tabular}

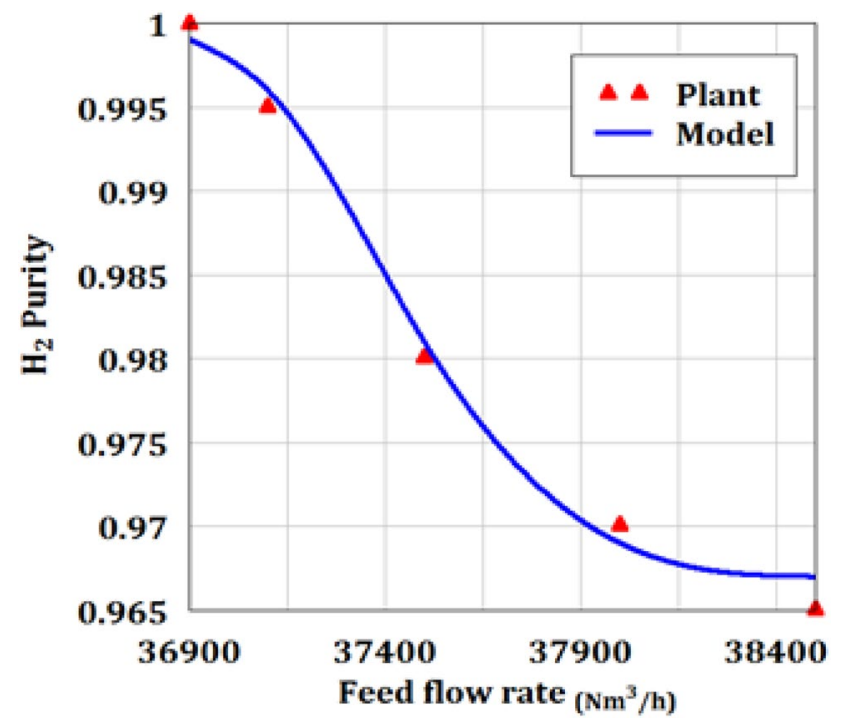

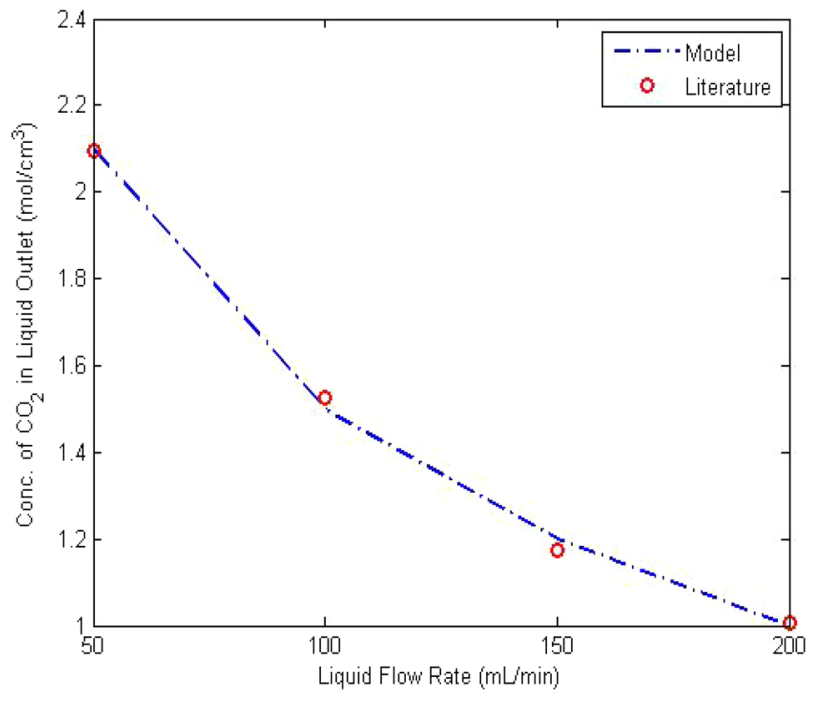

Fig. 5 The concentration of $\mathrm{CO}_{2}$ in the outlet liquid stream versus liquid flow rate

Table 10 Validation of the mathematical model in the methanol synthesis reactor

\begin{tabular}{lllc}
\hline Parameter & Plant & Model & Error (\%) \\
\hline $\mathrm{CH}_{3} \mathrm{OH}$ mole flow rate (mol/s) & 0.0315 & 0.034 & 7.35 \\
$\mathrm{H}_{2} \mathrm{O}$ mole flow rate (mol/s) & 0.0145 & 0.0151 & 3.97 \\
$\mathrm{H}_{2}$ mol flow rate (mol/s) & 0.35 & 0.345 & 1.44 \\
$\mathrm{CO}$ mole flow rate (mol/s) & 0.0152 & 0.0146 & 4.10 \\
$\mathrm{CO}_{2}$ mol flow rate $(\mathrm{mol} / \mathrm{s})$ & 0.046 & 0.041 & 12.19 \\
\hline
\end{tabular}

Error $=\left|\frac{X^{\text {exp. }}-X^{\text {cal. }}}{X^{\text {exp. }}}\right| \times 100$

The validity of $\mathrm{CO}_{2}$-MEA process results is evaluated through the empirical study of Sujatha Karoort which is about $\mathrm{CO}_{2}$ separation from the mixture of $\mathrm{CO}_{2} / \mathrm{N}_{2}$ [63].

Figure 5 shows the $\mathrm{CO}_{2}$ concentration in the outlet liquid stream versus liquid flow rate for the model prediction results in this work as well as the empirical results from other projects. It is obviously observed that the proposed model is in good agreement with the empirical data.

In addition, the validation of the results for the methanol synthesis reactor is performed using the empirical data from the industry. The obtained results from the proposed model and that of the plant are enlisted in Table 10. According to the presented error percentage, it can be understood that the difference between simulation results and empirical ones are reasonable. As a result, it can be concluded that in all the three cases, the simulation results are in good agreement with empirical ones.

Fig. $4 \mathrm{H}_{2}$ purity as a function input feed flow rate 

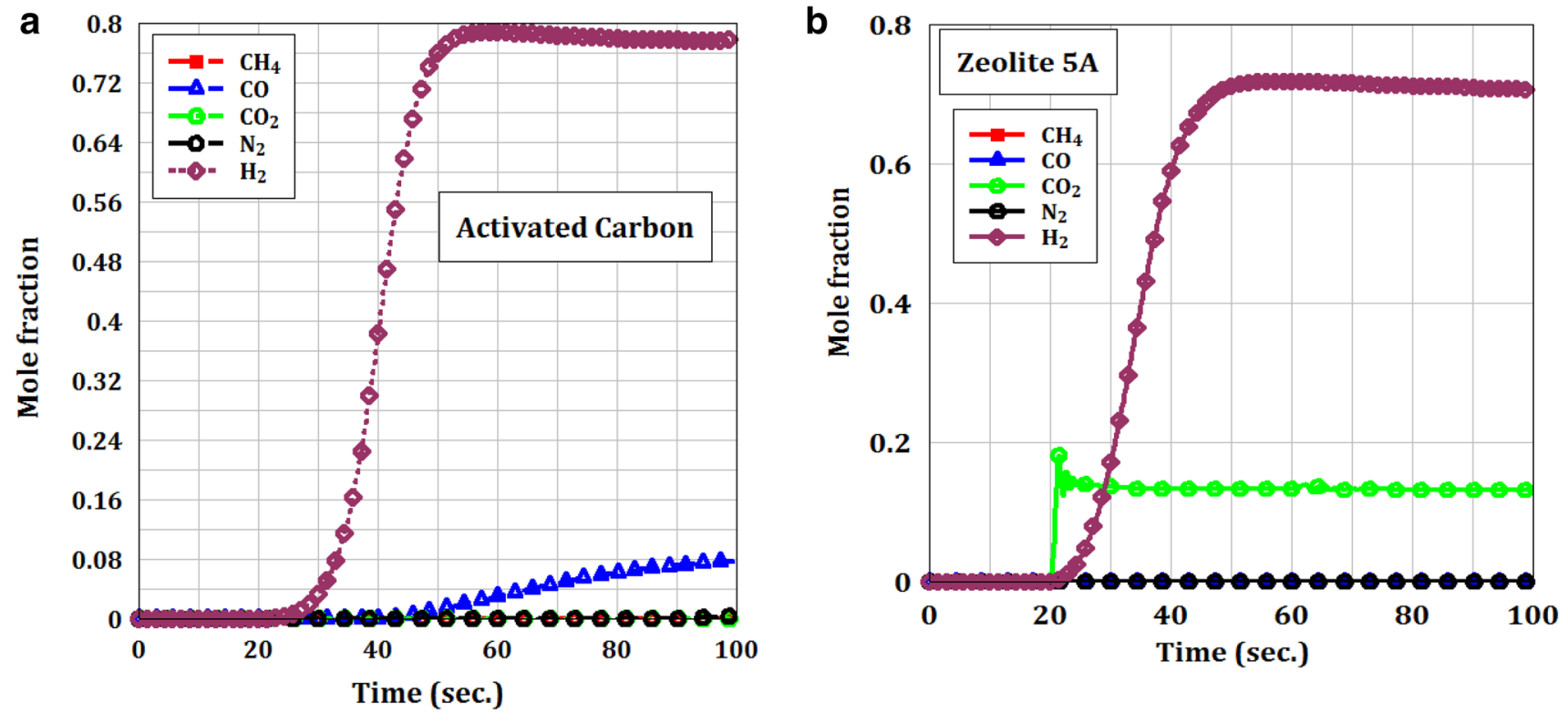

Fig. 6 a Molar fraction of components on activated carbon adsorbent versus time. b Molar fraction of components on 5A adsorbent versus time

\section{Results}

In this section, the results of simulation and mathematical modeling of the gas separation which is performed in two stages of absorption and adsorption are depicted. In addition, the simulation results of methanol synthesis from $\mathrm{CO}_{2}$ are presented.

\section{$\mathrm{H}_{2}$ separation through adsorption method in the first stage}

According to the simultaneous usage of two types of adsorbents, namely 5A and activated carbon, for the separation of hydrogen, the mole fraction of all existed components in flare gas against time on both activated carbon and 5A adsorbents has been plotted in Fig. 6a, b. In fact, Fig. 6 shows the breakthrough curves. The term "break-through" is originated from the response of initially cleaned bed per flow with a constant composition. As an initial condition, it is assumed that the adsorption bed is pressurized with a non-adsorptive gas. Regarding these two types of adsorbents, the adsorption capacity of components on two adsorbents can be determined. These two adsorbents have low adsorption capacity for hydrogen; hence, they are appropriate for implementing in hydrogen purification processes. It is worth mentioning that in prolonged time of the flare gas moving over the adsorption bed, activated carbon cannot remove all the carbon monoxide and carbon dioxide efficiently (because of the adsorption capacity of the adsorbents destroyed with along the time) and adsorption bed effluent will contain mentioned gases. Figure 7 shows the pressure variation in a six-stage

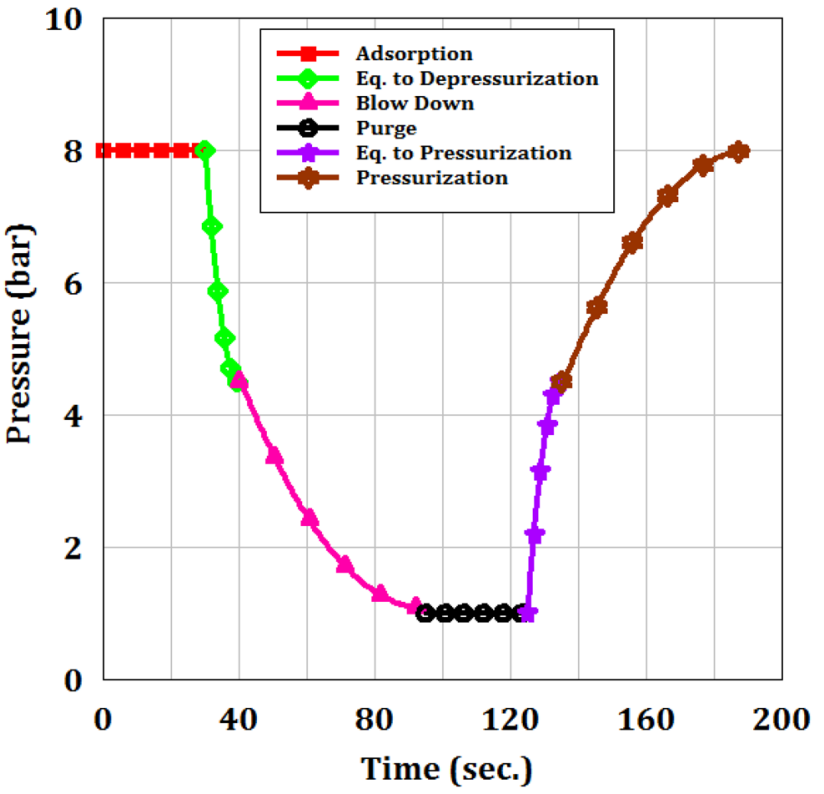

Fig. 7 The pressure variation in a six-stage 190-s cycle

190-s cycle. In the first $30 \mathrm{~s}$, considered as AD step, the pressure is constant. In the next $10 \mathrm{~s}$ which is known as ED step, bed pressure decreased from 8 to 4.5 bar. As a result of complete BD step in 55 s of the next stage, the bed faces an atmospheric pressure to be prepared for PG step. With the start of the PG step, the bed is maintained in this step for $30 \mathrm{~s}$. Enhancement in pressure from 1 to 4.5 bar caused by an EP step in $10 \mathrm{~s}$ provides the situation for higher pressure increase to achieve adsorption pressure under PR step. 

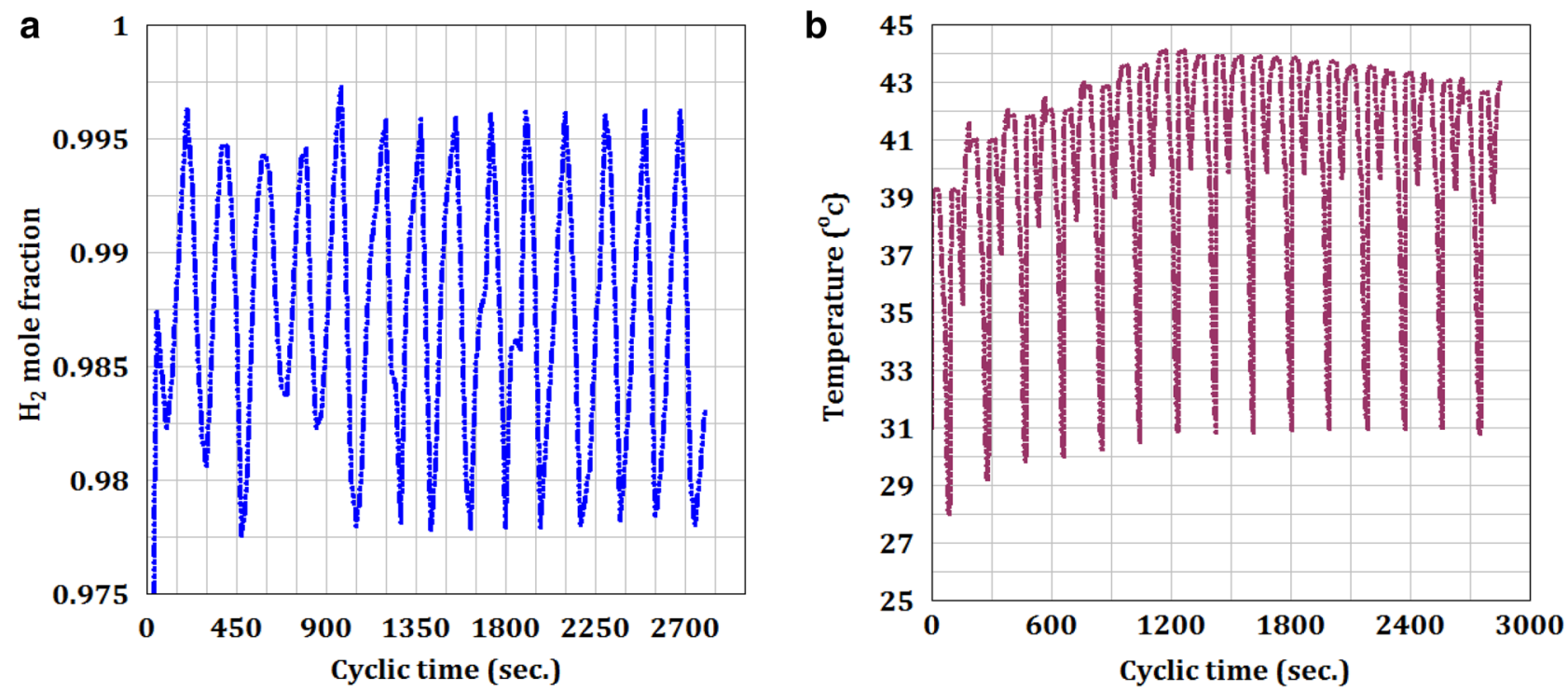

Fig. 8 a Mole fraction of hydrogen during consecutive cycles on top of the all six beds. $\mathbf{b}$ Bed temperature during consecutive cycles on top of the all six beds

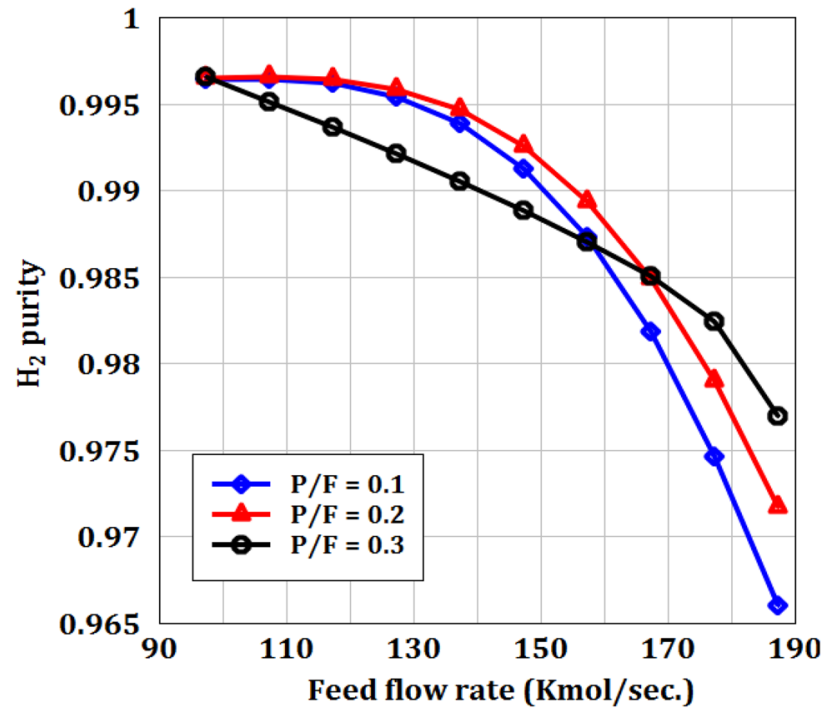

Fig. 9 Hydrogen purity versus feed flow rate and P/F of $0.1,0.2$ and 0.3

Figure $8 \mathrm{a}, \mathrm{b}$ presents variations in mole fraction of hydrogen and bed temperature during consecutive cycles on top of the beds, respectively. Sequential behavior of concentration, temperature and especially beds pressures is well presented in these figures. Due to the pressure variation of the bed during different adsorption process steps with the pressure swing, pressure curves are increasing and decreasing. These curves are ascending in PR and EP steps, while in BD and ED steps is falling. In both $\mathrm{AD}$ and $\mathrm{PG}$ steps, the pressure of the column will stay constant. As the beds are identical and

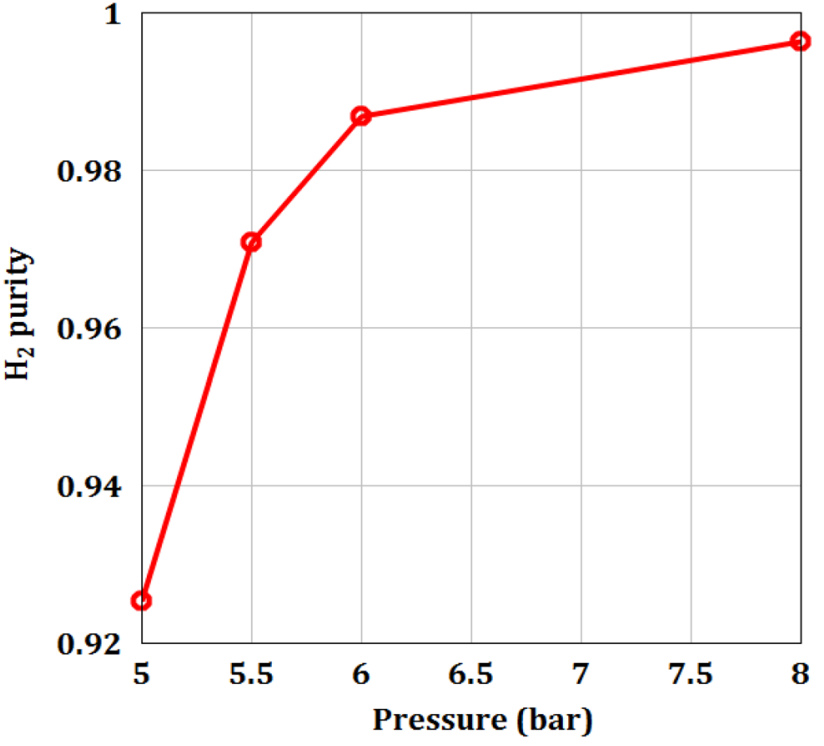

Fig. 10 Hydrogen purity as a function of adsorption stage pressure

perform similarly, the pressure curve is similar for each bed. Accordingly, hydrogen (volatile component) concentration increases on the top of the bed in high-pressure steps, while it is decreasing in low-pressure steps. It seems noteworthy that the adsorption process will reach a cyclic steady state (CSS) after several cycles. Hydrogen purity versus feed flow rate and purge-to-feed ration $(P / F)$ of $0.1,0.2$ and 0.3 have been plotted in Fig. 9. As it is obvious from the figure, hydrogen purity diminishes in higher inlet flow rates. It is perceivable from the curves that lower $P / F$ is desirable for 
lower flow rates while in higher flow rates; higher $P / F$ is advisable. Hydrogen purity as a function of AD step pressure is depicted in Fig. 10. This figure illustrates that product purity increases by pressure rise and, subsequently, a more suitable product will be attained for methanol production. Based on the obtained results from this figure, the efficient hydrogen separation is possible in the pressures range of 6-8 bar. However, special attention should be devoted to the

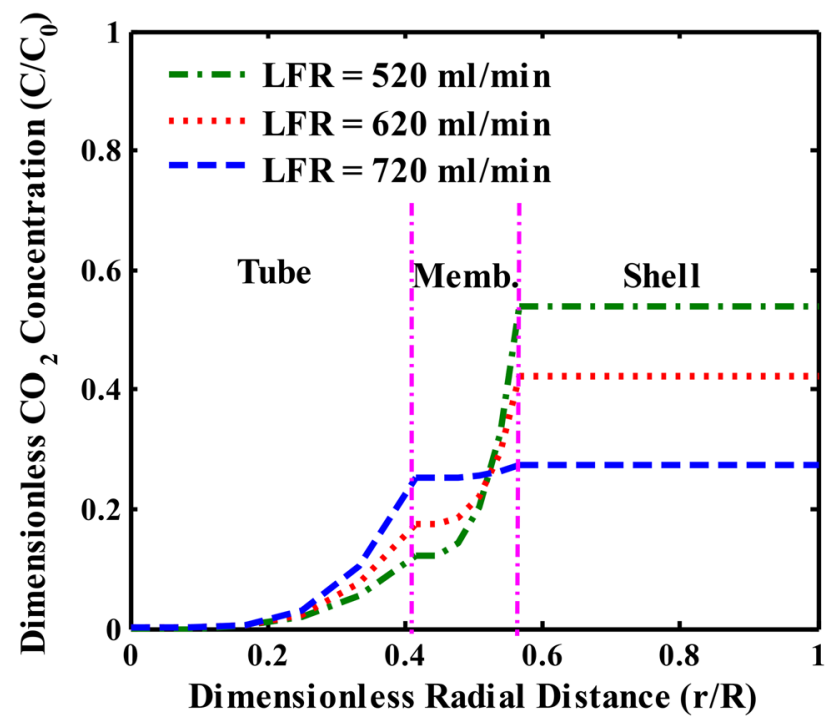

Fig. $11 \mathrm{CO}_{2}$ concentration profile in the radial direction for the different liquid flow rates in three sections of tube, membrane and shell

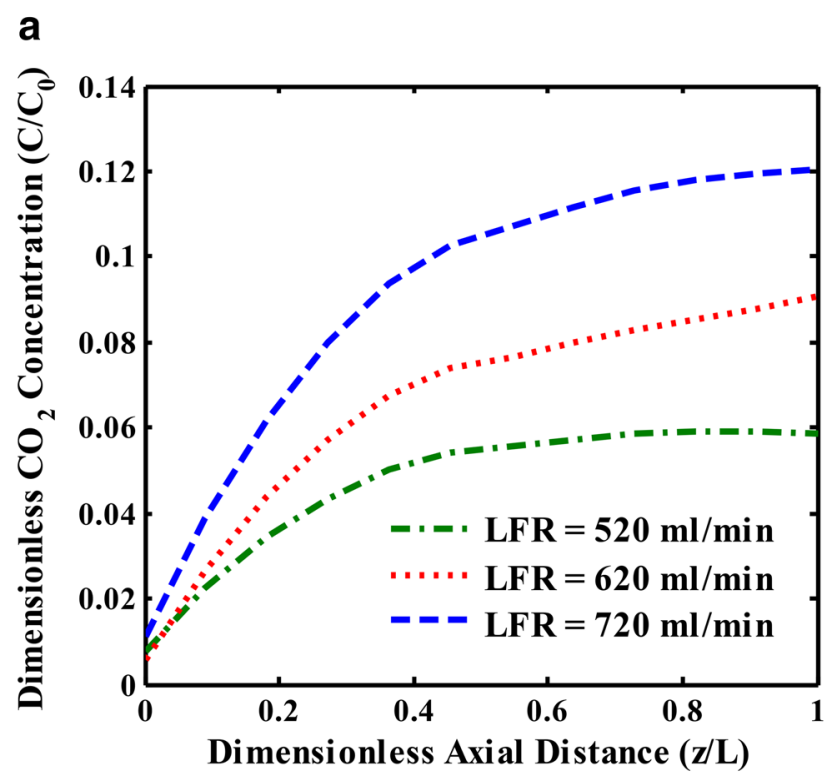

Fig. 12 a Dimensionless $\mathrm{CO}_{2}$ concentration versus dimensionless axial distance in different liquid flow rates and constant gas flow rate of $200 \mathrm{ml} / \mathrm{min}$ for the tube side. b Dimensionless $\mathrm{CO}_{2}$ concentration fact that the unit operating cost will escalate with pressure increment.

\section{$\mathrm{CO}_{2}$ separation through absorption through MEA solvent in the second stage}

$\mathrm{CO}_{2}$ concentration profile in the radial direction is shown in Fig. 11 for the different liquid flow rates in three sections of tube, membrane and shell. In this figure, the gas flow rate was constant at $200 \mathrm{ml} / \mathrm{min}$ when MEA is used as the adsorbent for the separation of $\mathrm{CO}_{2}$. As it is expected, the gas concentration slope is descending from the shell side to the membrane side and final to the tube side. In fact, the aim is to separate $\mathrm{CO}_{2}$ from the shell side and then solve it in the flowing solvent, which is obviously evident in different liquid flow rates. According to the figure, an increase in liquid flow rate leads to more removal of $\mathrm{CO}_{2}$ from the gas mixture. Since the concentration gradient in the membrane-tube surface increases when the solvent flow rate is higher and, thus, the mass transfer rate increases. Figure 12 shows variation in dimensionless $\mathrm{CO}_{2}$ concentration versus dimensionless axial distance in different liquid flow rates and constant gas flow rate of $200 \mathrm{ml} / \mathrm{min}$ for the tube side and shell side while MEA solvent is used. As per Fig. 12a, it can be observed that $\mathrm{CO}_{2}$ concentration increases with increase in dimensionless axial distance in the tube side. This trend is rational since the solvent absorbs more $\mathrm{CO}_{2}$ while moving in its path, and $\mathrm{CO}_{2}$ concentration grows up along the tube length. In addition, dimensionless $\mathrm{CO}_{2}$ concentration decreases with a decrease in liquid flow

b

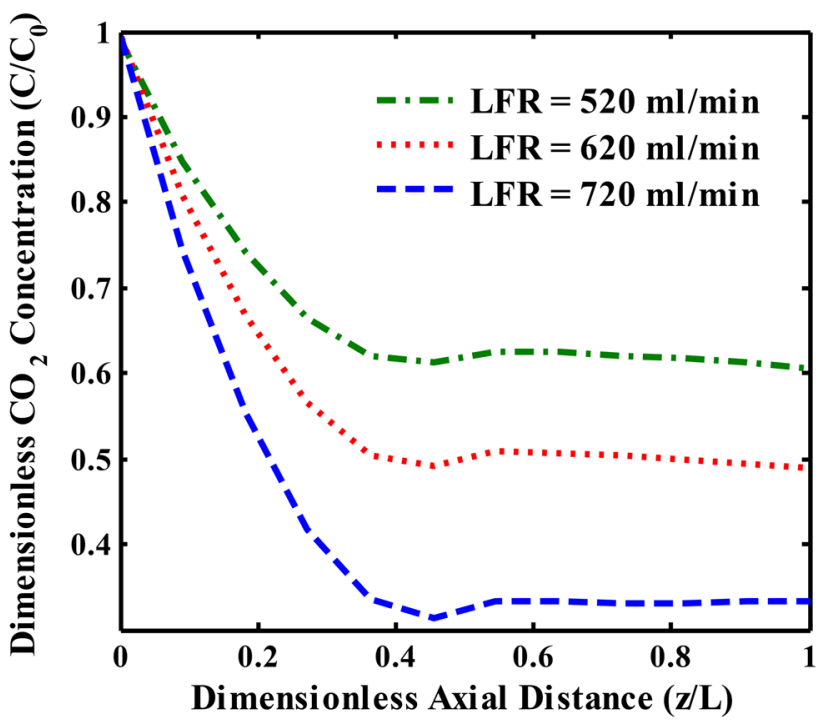

versus dimensionless axial distance in different liquid flow rates and constant gas flow rate of $200 \mathrm{ml} / \mathrm{min}$ for the shell side 
rate, since the lesser liquid flow rate causes solution rate decrease in the solvent and, therefore, mass transfer rate in tube-membrane surface decreases. As shown in Fig. 12b, the trend of variation in the shell side is descending because $\mathrm{CO}_{2}$ diffuses to the membrane, leading to a decrease in its concentration. On the other hand, with an increase in liquid flow rate, $\mathrm{CO}_{2}$ concentration decreases along the shell length. Actually, with an increase in liquid flow rate, owing to increase in concentration gradient in the membrane-tube surface, and subsequently, in the shell-membrane surface, it is rational that $\mathrm{CO}_{2}$ concentration more decreases along the shell length. Figure 13 demonstrates $\mathrm{CO}_{2}$ removal percentage versus variation in liquid and gas flow rates. With the increase in gas flow rate, $\mathrm{CO}_{2}$ removal percentage from the gas mixture reduces considering the fact that more gas flow velocity is; so the less time is available for the gas phase to diffuse into the membrane. Nevertheless, with an increase in liquid flow rate, since the liquid reclamation rate intensifies, the mass transfer occurs with a higher rate, and this is why $\mathrm{CO}_{2}$ removal percentage grows up.

\section{Evaluation of a proposed method of methanol production from $\mathrm{CO}_{2}$}

In this section, the operability of methanol synthesis from $\mathrm{CO}_{2}$ reactor is evaluated in their different conditions, which is named as follows:

1- Industrial unit in its conventional type with the gas mixture feed of $\mathrm{CO}, \mathrm{CO}_{2}, \mathrm{H}_{2}$ and $\mathrm{H}_{2} \mathrm{O}$.

2- Industrial unit in which $\mathrm{CO}_{2}$ is fed instead of $\mathrm{CO}$.

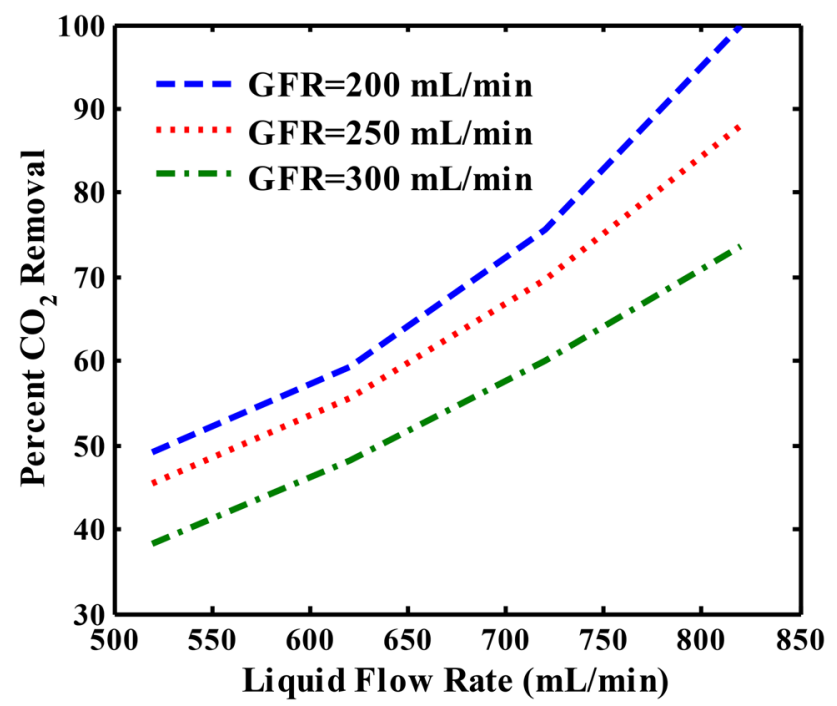

Fig. $13 \mathrm{CO}_{2}$ removal percentage versus variation in liquid and gas flow rates
3- Regarding the kinetic of methanol production reaction from $\mathrm{CO}_{2}$, for $1 \mathrm{~mol}$ of $\mathrm{CO}_{2}, 3 \mathrm{~mol}$ of $\mathrm{H}_{2}$ is fed into the reactor.

Figure 14 compares the performance of methanol synthesis reactors in three cases. The molar fraction of $\mathrm{CO}, \mathrm{CO}_{2}$ and $\mathrm{H}_{2}$ is illustrated through the reactor length. As shown in Fig. 14a, $\mathrm{CO}$ is just entered into the reactor as the feed in the industrial case (case (1)), and in two other cases $\mathrm{CO}$ concentration is considered zero. In the cases (2) and (3), CO molar fraction increases along the reactor length because $\mathrm{H}_{2} \mathrm{O}$ is produced by the reaction of methanol synthesis through $\mathrm{CO}_{2}$, and then it reacts with the existing $\mathrm{CO}_{2}$ through WGS reaction. As per Fig. 14b, it can be observed that molar fraction of $\mathrm{CO}_{2}$ decreases along the reactor length owing to its consumption in all the three cases. As shown in Fig. 14c, $\mathrm{H}_{2}$ molar fraction demonstrated along the reactor length. Considering that the ratio of $\mathrm{H}_{2}$ to $\mathrm{CO}_{2}$ is $3\left(\mathrm{H}_{2} / \mathrm{CO}_{2}=3\right)$. Since $\mathrm{H}_{2}$ is one of the reactants in methanol production reaction, its molar rate decreases along the reactor length. Figure $14 \mathrm{~d}$ shows the molar flow rate of methanol versus dimensionless reactor length. According to this figure, methanol production rate in the cases at which $25 \%$ of the feed is $\mathrm{CO}_{2}$ and $75 \%$ of $\mathrm{H}_{2}$, approximately is equal to the methanol production rate from the synthesis gas in case (1). Besides, it shows $\mathrm{H}_{2}$ and $\mathrm{CO}_{2}$ conversion percentage. As in Fig. 14e, it is evident that the highest conversion percentage of $\mathrm{H}_{2}$ can be achieved in case (3), and the reason for this result is the appropriate ratio of the input components to the reactor. The lowest $\mathrm{H}_{2}$ conversion percentage is obtained in case (2) since in this case the $\mathrm{CO}$ concentration is considered zero, and $\mathrm{CO}_{2}$ is fed instead of CO. As per Fig. 14f, it can be observed that $\mathrm{CO}_{2}$ conversion in the case (2) is higher than two others. It may seem that this figure contradicts the results of previous figures; however, it should be emphasized that the conversion percentage is the ratio of the converted amount to the amount fed and consequently in case (3), with higher $\mathrm{CO}_{2}$ flow rate in the feed, it is reasonable to observe higher conversion percentage in case (3) than case (2). However, in case (1) it remains to be asked why in this case the input $\mathrm{CO}_{2}$ is lower than that of other cases, why the mentioned results have not been obtained. To explain, this result is due to the existence of $\mathrm{CO}$ in case (1). In the kinetic of methanol production, $1 \mathrm{~mol}$ of $\mathrm{CO}$ reacts with $2 \mathrm{~mol}$ of $\mathrm{H}_{2}$ while $1 \mathrm{~mol}$ of $\mathrm{CO}_{2}$ reacts with $3 \mathrm{~mol}$ of $\mathrm{H}_{2}$, and thus the former reaction (with $\mathrm{CO}$ ) occurs more than the latter $\left(\mathrm{CO}_{2}\right)$, and this is why conversion percentage decreases in this case. 

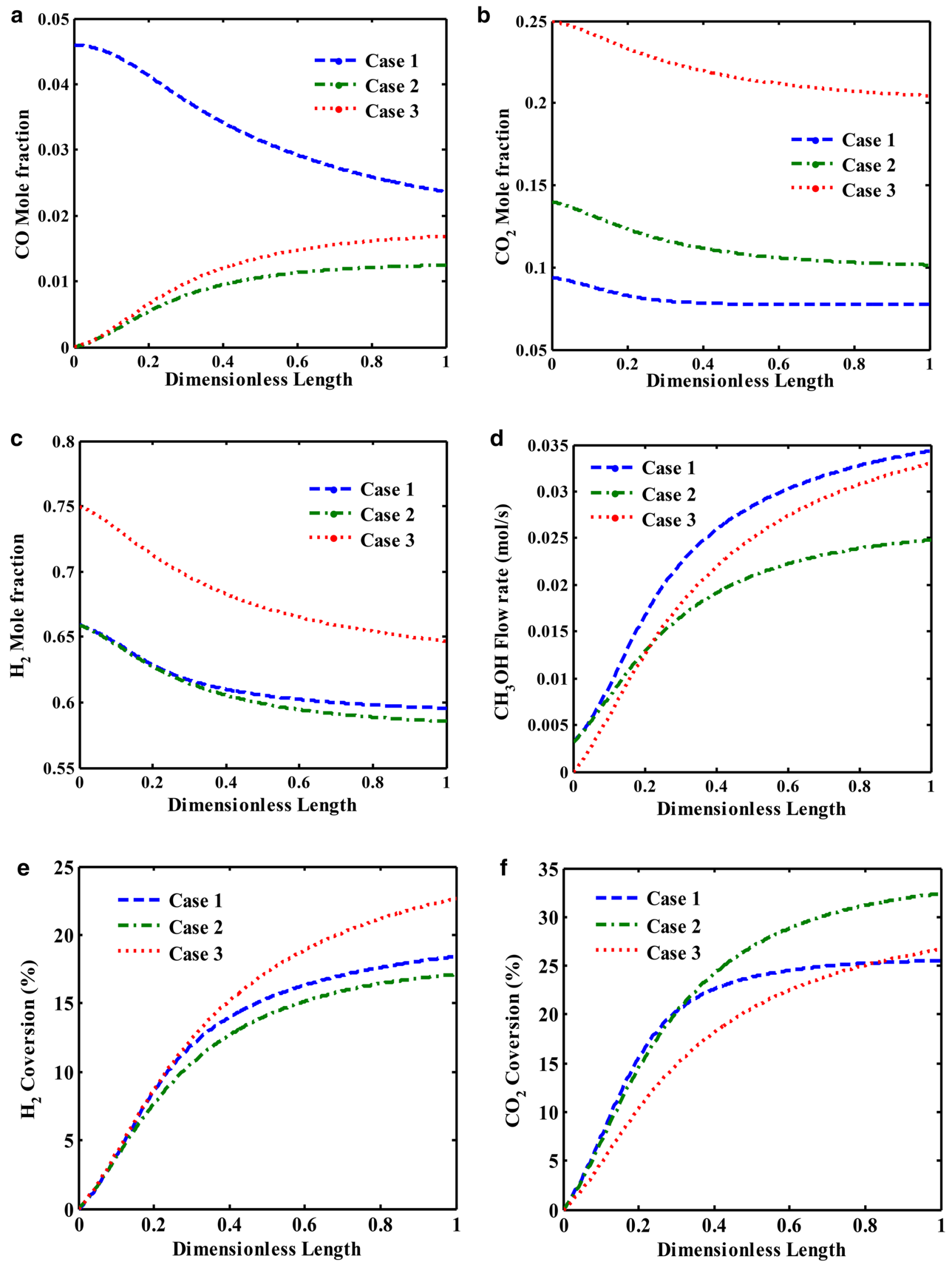
४Fig. 14 a Comparison between the variation of CO molar fraction in the three flow cases vs. methanol reactor length. b Comparison between the variations of $\mathrm{CO}_{2}$ molar fraction in the three flow cases vs. methanol reactor length. c Comparison between the variations of $\mathrm{H}_{2}$ molar fraction in the three flow cases vs. methanol reactor length. d Comparison between the variations of $\mathrm{CH}_{3} \mathrm{OH}$ molar flow rate in the three flow cases vs. methanol reactor length. e Comparison between the variations of $\mathrm{H}_{2}$ conversion in the three flow cases vs. methanol reactor length. $\mathbf{f}$ Comparison between the variations of $\mathrm{CO}_{2}$ conversion in the three flow cases vs. methanol reactor length

\section{Conclusion}

In this investigation, two subjects are evaluated through simulation of mathematical models including (1) separation of $\mathrm{H}_{2}$ and $\mathrm{CO}_{2}$ from the flare gas $\left(\mathrm{N}_{2} / \mathrm{CH}_{4} / \mathrm{CO} / \mathrm{CO}_{2} / \mathrm{H}_{2}\right)$ with sorbent/ solvent method, (2) presentation and evaluation of methanol production from $\mathrm{CO}_{2}$, and comparison between three different cases of input feed. In addition, the results of simulation through selected models are validated through comparison with those results which are obtained by simulation of empirical data. With this purpose in mind, separation through sorbent/solvent method is studied while a gas mixture that is analogous to real flare gas is considered. Results of simulation illustrate that owing to a high volume of $\mathrm{H}_{2}$ in the inlet as well as simplicity of separation through PSA method, the first stage of separation is preferred to be performed through PSA method, while activated carbon and zeolite 5A are used as the sorbents. In addition, some influential parameters such as $P / F$ and pressure are evaluated to simulate the best separation process. In the next separation stage, $\mathrm{CO}_{2}$ is separated from the outlet stream of the first stage of separation $\left(\mathrm{N}_{2} / \mathrm{CO} / \mathrm{CO}_{2} / \mathrm{CH}_{4}\right)$ through MEA solvent. In this stage, according to the obtained results, the best gas and liquid (solvent) flow rates are $200 \mathrm{ml} / \mathrm{min}$ and $720 \mathrm{ml} / \mathrm{min}$, respectively. Also, results show that the recycled gas flow rate is $473.37 \mathrm{kmol} / \mathrm{h}$, and $99.83 \% \mathrm{CO}_{2}$ and $75 \% \mathrm{H}_{2}$ can be removed from the gas mixture. The simulation results for the second part (methanol production) demonstrate that methanol production flow rate is $0.0344 \mathrm{~mol} / \mathrm{s}, 0.0248 \mathrm{~mol} / \mathrm{s}$ and $0.0330 \mathrm{~mol} / \mathrm{s}$ for cases (1), (2) and (3), respectively. Furthermore, methanol production of the case (1) is approximately close to that of the case (3), and it is reduced $4 \%$ in case (3).

Open Access This article is distributed under the terms of the Creative Commons Attribution 4.0 International License (http://creativeco mmons.org/licenses/by/4.0/), which permits unrestricted use, distribution, and reproduction in any medium, provided you give appropriate credit to the original author(s) and the source, provide a link to the Creative Commons license, and indicate if changes were made.

\section{References}

1. Andersen RD, Assembayev DV, Bilalov R, Duissenov D, Shutemov D (2012) Efforts to reduce flaring and venting of natural gas world-wide. Norwegian University of Science and Technology, Trondheim

2. Emam EA (2015) Gas flaring in industry: an overview. Pet Coal 57(5):532-555

3. Rao RS, Krishna MKVSG, Subrahmanyam A (2014) Challenges in oil and gas industry for major fire and gas leaks-risk reduction methods. Int J Res Eng Technol 3(16)

4. Ghadyanlou F, Vatani A (2015) Flare-gas recovery methods for olefin plants. Chem Eng 122(5):66

5. Emam EA (2016) Environmental pollution and measurement of gas flaring. Int J Innov Res Sci Eng Technol 2:252-262

6. Sangsaraki ME, Anajafi E (2015) Design criteria and simulation of flare gas recovery system. In: International conference on chemical, food and environment engineering (ICCFEE'15). Dubai

7. Rahimpour MR, Jokar SM (2012) Feasibility of flare gas reformation to practical energy in Farashband gas refinery: no gas flaring. J Hazard Mater 209:204-217

8. Ezersky A, Lips H (2003) Characterisation of refinery flare emissions: assumptions, assertions and AP-42. Bay area air quality management district (BAAQMD)

9. Ghorbani M, Koocheki A, Motallebi M (2008) Estimating the greenhouse gases emission and the most important factors in dairy farms (Case Study Iran). J Appl Sci 8(23):252-262

10. Soltanieh M, Zohrabian A, Gholipour MJ, Kalnay E (2016) A review of global gas flaring and venting and impact on the environment: case study of Iran. Int J Greenh Gas Control 49:488-509

11. Nabhani N, Mirdrikvand M, Moqadam SI, Rezazadeh A, Sakaki SA (2012) Monitoring greenhouse gases and their pollutions in Sarakhs region influenced by the sourest natural gas resource in the middle east. Environ Pollut 2(1):27

12. Kangwanwatana W, Saiwan C, Tontiwachwuthikul P (2013) Study of $\mathrm{CO}_{2}$ adsorption using adsorbent modified with piperazine. Chem Eng Trans 35:403-408

13. Khanipour M, Mirvakilib A, Bakhtyaria A, Farniaeic M, Rahimpour MR (2017) Enhancement of synthesis gas and methanol production by flare gas recovery utilizing a membrane based separation process. Fuel Process Technol 166:186-201

14. Agahzamin S, Mirvakili A, Rahimpour M (2016) Investigation and recovery of purge gas streams to enhance synthesis gas production in a mega methanol complex. J CO2 Utilization 16:157-168

15. Harlick P, Tezel F (2003) Adsorption of carbon dioxide, methane and nitrogen: pure and binary mixture adsorption for ZSM-5 with $\mathrm{SiO} 2 / \mathrm{Al} 2 \mathrm{O} 3$ ratio of 280. Sep Purif Technol 33(2):199-210

16. Li J-R, Ma Y, McCarthy MC, Sculley J, Yu J, Jeong H-K, Balbuena PB, Zhou H-C (2011) Carbon dioxide capture-related gas adsorption and separation in metal-organic frameworks. Coord Chem Rev 255(15):1791-1823

17. Olivares-Marín M, Maroto-Valer MM (2012) Development of adsorbents for $\mathrm{CO} 2$ capture from waste materials: a review. Greenh Gases Sci Technol 2(1):20-35

18. You YW, Lee DG, Yoon KY, Moon DK, Kim SM, Lee CH (2012) $\mathrm{H} 2$ PSA purifier for CO removal from hydrogen mixtures. Int $\mathbf{J}$ Hydrog Energy 37(23):18175-18186

19. Huang Q, Malekian A, Eić M (2008) Optimization of PSA process for producing enriched hydrogen from plasma reactor gas. Sep Purif Technol 62(1):22-31

20. Grande CA, Lopes FV, Ribeiro AM, Loureiro JM, Rodrigues AE (2008) Adsorption of off-gases from steam methane reforming (H2, CO2, CH4, CO and N2) on activated carbon. Sep Sci Technol 43(6):1338-1364

21. Papadias DD, Ahmed S, Kumar R, Joseck F (2009) Hydrogen quality for fuel cell vehicles-a modeling study of the sensitivity of impurity content in hydrogen to the process variables in the SMR-PSA pathway. Int J Hydrog Energy 34(15):6021-6035

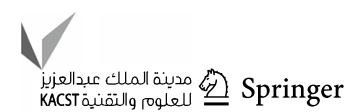


22. Yang S-I, Choi D-Y, Jang S-C, Kim S-H, Choi D-K (2008) Hydrogen separation by multi-bed pressure swing adsorption of synthesis gas. Adsorption 14(4-5):583-590

23. Silva B, Solomon I, Ribeiro AM, Lee U-H, Hwang YK, Chang J-S, Loureiro JM, Rodrigues AE (2013) H 2 purification by pressure swing adsorption using CuBTC. Sep Purif Technol 118:744-756

24. Agueda VI, Delgado JA, Uguina MA, Brea P, Spjelkavik AI, Blom $\mathrm{R}$, Grande C (2015) Adsorption and diffusion of $\mathrm{H} 2, \mathrm{~N} 2, \mathrm{CO}$, $\mathrm{CH} 4$ and $\mathrm{CO} 2$ in UTSA-16 metal-organic framework extrudates. Chem Eng Sci 124:159-169

25. Delgado JA, Agueda VI, Uguina MA, Sotelo JL, Brea P (2015) Hydrogen recovery from off-gases with nitrogen-rich impurity by pressure swing adsorption using $\mathrm{CaX}$ and $5 \mathrm{~A}$ zeolites. Adsorption 21(1-2):107-123

26. Hajizadeh A, Mohamadi-Baghmolaei M, Azin R, Osfouri Sh, Heydari I (2018) Technical and economic evaluation of flare gas recovery in a giant gas refinery. Chem Eng Res Design. https:// doi.org/10.1016/j.cherd.2017.11.026

27. Javadi Shokroo E (2018) Nitrogen, methane and ethane recovery from a domestic petrochemical flare gas by using pressure swing adsorption system, Ph.D. Thesis in Chemical Engineering, Selinus University of Science and Literature. https://doi.org/10.13140 /RG.2.2.33129.34407

28. Yu C-H, Huang C-H, Tan C-S (2012) A review of CO2 capture by absorption and adsorption. Aerosol Air Qual Res 12(5):745-769

29. He Q, Chen M, Meng L, Liu K, Pan WP (2004) Study on carbon dioxide removal from flue gas by absorption of aqueous ammonia. Institute for Combustion Science and Environmental Technology

30. Devries N (2014) CO2 absorption into concentrated carbonate solutions with promoters at elevated temperatures. M.S. Thesis in Agricultural \& Biological Engineering, University of Illinois at Urbana-Champaign

31. Sayari A, Belmabkhout Y, Serna-Guerrero R (2011) Flue gas treatment via CO 2 adsorption. Chem Eng J 171(3):760-774

32. Rochelle GT (2009) Amine scrubbing for $\mathrm{CO} 2$ capture. Science 325(5948):1652-1654

33. Nagy T, Mizsey P (2015) Model verification and analysis of the CO 2-MEA absorber-desorber system. Int J Greenh Gas Control 39:236-244

34. Luis $\mathrm{P}$ (2016) Use of monoethanolamine (MEA) for CO 2 capture in a global scenario: consequences and alternatives. Desalination 380:93-99

35. Li K, Leigh W, Feron P, Yu H, Tade M (2016) Systematic study of aqueous monoethanolamine (MEA)-based CO 2 capture process: techno-economic assessment of the MEA process and its improvements. Appl Energy 165:648-659

36. Bayat M, Rahimpour M, Taheri M, Pashaei M, Sharifzadeh S (2012) A comparative study of two different configurations for exothermic-endothermic heat exchanger reactor. Chem Eng Process 52:63-73

37. Rahimpour M, Mostafazadeh AK, Barmaki M (2008) Application of hydrogen-permselective Pd-based membrane in an industrial single-type methanol reactor in the presence of catalyst deactivation. Fuel Process Technol 89(12):1396-1408

38. Semelsberger TA, Borup RL, Greene HL (2006) Dimethyl ether (DME) as an alternative fuel. J Power Sources 156(2):497-511

39. Graaf G, Scholtens H, Stamhuis E, Beenackers A (1990) Intraparticle diffusion limitations in low-pressure methanol synthesis. Chem Eng Sci 45:773-783

40. Graaf G, Sijtsema P, Stamhuis E, Joosten G (1986) Chemical equilibria in methanol synthesis. Chem Eng Sci 41(11):2883-2890

41. Methanol documents of Lurgi in Assaluyeh-Iran

42. Al-Marzouqi M, El-Naas M, Marzouk S, Abdullatif N (2008) Modeling of chemical absorption of $\mathrm{CO} 2$ in membrane contactors. Sep Purif Technol 62(3):499-506
43. Cussler EL (2009) Diffusion: mass transfer in fluid systems. Cambridge University Press, Cambridge

44. Versteeg G, van Swaaij WPM (1988) On the kinetics between CO2 and alkanolamines both in aqueous and non-aqueous solutions-I. Primary and secondary amines. Chem Eng Sci 43(3):573-585

45. Barth D, Tondre C, Delpuech JJ (1986) Stopped-flow investigations of the reaction kinetics of carbon dioxide with some primary and secondary alkanolamines in aqueous solutions. Int J Chem Kinet 18(4):445-457

46. Bird RB, Stewart WE, Lightfoot EN (1960) Transport phenomena. Wiley, New York, p 780

47. Versteeg G, Van Dijck L, van Swaaij WPM (1996) On the kinetics between $\mathrm{CO} 2$ and alkanolamines both in aqueous and non-aqueous solutions-an overview. Chem Eng Commun 144(1):113-158

48. Happel J (1959) Viscous flow relative to arrays of cylinders. AIChE J 5(2):174-177

49. Kreulen H, Smolders C, Versteeg G, van Swaaij WPM (1993) Microporous hollow fibre membrane modules as gas-liquid contactors. Part 1. Physical mass transfer processes: a specific application: mass transfer in highly viscous liquids. J Membr Sci 78(3):197-216

50. Kreulen H, Smolders C, Versteeg G, van Swaaij WPM (1993) Microporous hollow fibre membrane modules as gas-liquid contactors part 2. Mass transfer with chemical reaction. J Membr Sci 78(3):217-238

51. Reynolds SP, Ebner AD, Ritter JA (2006) Enriching PSA cycle for the production of nitrogen from air. Ind Eng Chem Res 45(9):3256-3264

52. Kostroski KP, Wankat PC (2006) High recovery cycles for gas separations by pressure-swing adsorption. Ind Eng Chem Res 45(24):8117-8133

53. Jee J-G, Kim M-B, Lee C-H (2005) Pressure swing adsorption processes to purify oxygen using a carbon molecular sieve. Chem Eng Sci 60(3):869-882

54. Teague KG, Edgar TF (1999) Predictive dynamic model of a small pressure swing adsorption air separation unit. Ind Eng Chem Res 38(10):3761-3775

55. Wilson SJ, Beh CC, Webley PA, Todd RS (2001) The effects of a readily adsorbed trace component (water) in a bulk separation PSA process: the case of oxygen VSA. Ind Eng Chem Res 40(12):2702-2713

56. Cruz P, Magalhaes F, Mendes A (2005) On the optimization of cyclic adsorption separation processes. AIChE J 51(5):1377-1395

57. Jain S, Moharir A, Li P, Wozny G (2003) Heuristic design of pressure swing adsorption: a preliminary study. Sep Purif Technol 33(1):25-43

58. Jee J-G, Kim M-B, Lee C-H (2001) Adsorption characteristics of hydrogen mixtures in a layered bed: binary, ternary, and fivecomponent mixtures. Ind Eng Chem Res 40(3):868-878

59. Methanol documents in Jam, Iran

60. Javadi Shokroo E, Shahcheraghi M, Farniaei M (2014) Numerical simulation of a H2-PSA case study: the Jam petrochemical industrial plant in the southern pars zone. Pet Coal J 56(1):61-66

61. Santos JC, Portugal AF, Magalhaes FD, Mendes A (2004) Simulation and optimization of small oxygen pressure swing adsorption units. Ind Eng Chem 43:8328-8338

62. Ritter JA, Liu Y (1998) Tapered pressure swing adsorption columns for simultaneous air purification and solvent vapor recovery. Ind Eng Chem Res 37(7):2783-2791

63. Karoor S, Sirkar KK (1993) Gas absorption studies in microporous hollow fiber membrane modules. Ind Eng Chem Res 32(4):674-684

Publisher's Note Springer Nature remains neutral with regard to jurisdictional claims in published maps and institutional affiliations. 


\section{Affiliations}

\section{Ali Zare ${ }^{1} \cdot$ Mina Khanipour $^{2} \cdot$ Hojjat Khorrami Sarverstani ${ }^{3} \cdot$ Iman Ahmadi Kakavandi ${ }^{6} \cdot$ Ehsan Javadi Shokroo ${ }^{4,5} \odot$. Mehdi Farniaei $^{5} \cdot$ Mehdi Baghbani $^{6}$}

1 Department of Chemical Engineering, AmirKabir University of Technology (Tehran Polytechnic), P.O. Box 15875-4413, Tehran, Iran

2 School of Chemical and Petroleum Engineering, Chemical Engineering Department, Shiraz University, Shiraz, Iran

3 Chemical Engineering Department, Islamic Azad University, Shiraz Branch, Shiraz, Iran
4 Chemical Engineering Department, Faculty of Engineering, Selinus University of Sciences and Literature, 40138 Bologna, BO, Italy

5 Department of Research and Development, FAPKCO Engineering Group, Shiraz 888 41111, Iran

6 Commercialization Department, FAPKCO Engineering Group, Shiraz, Iran 